\title{
Hydrologic-land surface modelling of the Canadian sporadic-discontinuous permafrost: initialization and uncertainty propagation
}

\author{
Mohamed Abdelhamed ${ }^{1}$, Mohamed Elshamy ${ }^{1}$, Howard Wheater ${ }^{1}$, and Saman Razavi ${ }^{1}$ \\ ${ }^{1}$ University of Saskatchewan
}

April 26, 2021

\begin{abstract}
Permafrost thaw has been observed in recent decades in the Northern Hemisphere and is expected to accelerate with continued global warming. Predicting the future of permafrost requires proper representation of the interrelated surface/subsurface thermal and hydrologic regimes. Land surface models (LSMs) are well suited for such predictions, as they couple heat and water interactions across soil-vegetation-atmosphere interfaces and can be applied over large scales. LSMs, however, are challenged by the long-term thermal and hydraulic memories of permafrost and the paucity of historical records to represent permafrost dynamics under transient climate conditions. In this study, we address the challenge of model initialization by characterizing the impact of initial climate conditions and initial soil frozen and liquid water contents on the simulation length required to reach equilibrium. Further, we quantify how the uncertainty in model initialization propagates to simulated permafrost dynamics. Modelling experiments are conducted with the Modélisation Environmentale Communautaire - Surface and Hydrology (MESH) framework and its embedded Canadian Land Surface Scheme (CLASS). The study area is in the Liard River basin in the Northwest Territories of Canada with sporadic and discontinuous regions. Results show that uncertainty in model initialization controls various attributes of simulated permafrost, especially the active layer thickness, which could change by $0.5-1.5 \mathrm{~m}$ depending on the initial condition chosen. The least number of spin-up cycles is achieved with near field capacity condition, but the number of cycles varies depending on the spin-up year climate. We advise an extended spin-up of 200-1000 cycles to ensure proper model initialization under different climatic conditions and initial soil moisture contents.
\end{abstract}

Mohamed S. Abdelhamed ${ }^{1,2,3}$, Mohamed E. Elshamy ${ }^{1}$, Howard S. Wheater ${ }^{1,2,4,5}$, Saman Razavi ${ }^{1,2,4}$

${ }^{1}$ Global Institute for Water Security, University of Saskatchewan, Saskatoon, Saskatchewan, Canada

${ }^{2}$ Department of Civil, Environmental, and Geological Engineering, University of Saskatchewan, Saskatoon, Saskatchewan, Canada

${ }^{3}$ Department of Irrigation and Hydraulics Engineering, Cairo University, Giza, Egypt

${ }^{4}$ School of Environment and Sustainability, University of Saskatchewan, Saskatoon, Saskatchewan, Canada

${ }^{5}$ Department of Civil and Environmental Engineering, Imperial College London, London, United Kingdom

Corresponding author: Mohamed S. Abdelhamed, Global Institute for Water Security, University of Saskatchewan, National Hydrology Research Centre, 11 Innovation Boulevard, Saskatoon, SK, S7N 3H5, Canada. Email: Mohamed.abdelhamed@usask.ca

Running Title: Initialization and Uncertainty of Permafrost Simulations

Keywords: Permafrost, Initialization, Land Surface Models, Spin-up, Uncertainty, Liard River 


\begin{abstract}
Permafrost thaw has been observed in recent decades in the Northern Hemisphere and is expected to accelerate with continued global warming. Predicting the future of permafrost requires proper representation of the interrelated surface/subsurface thermal and hydrologic regimes. Land surface models (LSMs) are well suited for such predictions, as they couple heat and water interactions across soil-vegetation-atmosphere interfaces and can be applied over large scales. LSMs, however, are challenged by the long-term thermal and hydraulic memories of permafrost and the paucity of historical records to represent permafrost dynamics under transient climate conditions. In this study, we address the challenge of model initialization by characterizing the impact of initial climate conditions and initial soil frozen and liquid water contents on the simulation length required to reach equilibrium. Further, we quantify how the uncertainty in model initialization propagates to simulated permafrost dynamics. Modelling experiments are conducted with the Modélisation Environmentale Communautaire - Surface and Hydrology (MESH) framework and its embedded Canadian Land Surface Scheme (CLASS). The study area is in the Liard River basin in the Northwest Territories of Canada with sporadic and discontinuous regions. Results show that uncertainty in model initialization controls various attributes of simulated permafrost, especially the active layer thickness, which could change by $0.5-1.5 \mathrm{~m}$ depending on the initial condition chosen. The least number of spin-up cycles is achieved with near field capacity condition, but the number of cycles varies depending on the spin-up year climate. We advise an extended spin-up of 200-1000 cycles to ensure proper model initialization under different climatic conditions and initial soil moisture contents.
\end{abstract}

\title{
INTRODUCTION
}

Permafrost, defined as perennially cryotic ground for at least two consecutive years (Everdingen, 1998), is a critical feature in cold regions that substantially impacts hydrology, energy flux partitioning, plant communities and carbon dynamics. One-half of Canada and one-quarter of the Northern Hemisphere are underlain by permafrost (Zhang et al. , 1999). Permafrost thaw has been observed in recent decades in North America and Eurasia (DeBeer et al. , 2016; Pan et al. , 2016; Meredith et al. , 2020) and is expected to accelerate with global warming (Zhang et al., 2008a; Lawrence et al. , 2012). CMIP5 results showed a projected areal loss of permafrost in the northern regions of between 30\% to 90\%, with most of the loss occurring by the end of the $21^{\text {st }}$ century (McGuireet al., 2018). Similarly, Burke et al. (2020) reported projected permafrost degradation of the upper $2 \mathrm{~m}$ of soil of $10 \%-40 \%$ per $1.0^{\circ} \mathrm{C}$ increase in global mean air temperature from the CMIP6 multi-model ensemble. Notably, permafrost contains twice the amount of carbon stored in the atmosphere, the release of which would accelerate the pace of global warming via a positive feedback mechanism (Schuuret al. , 2015; Walvoord and Kurylyk, 2016). Other implications of permafrost thaw include changes to hydrologic connectivity through the formation of vertical and lateral taliks, which in turn affects water fluxes and storage, slope stability and land subsidence, and ecosystem changes including shifts in vegetation structure and streamflow seasonality (Nelson et al. , 2002; Dobinski, 2011; Woo, 2012; Hjort et al. , 2018).

Extensive modelling efforts have focused on permafrost at regional and global scales (Wright et al. , 2003; Lawrence and Slater, 2005; Riseborough et al. , 2008; Zhang et al. , 2013). According to Riseborough et al . (2008), permafrost models can be grouped into three categories. Empirical models are essentially statistical, attribute the occurrence of permafrost to topo-climatic factors (e.g. altitude, air temperature, and slope/aspect) and employ empirically-derived landscape parameters to represent the response of permafrost to climatic and local conditions (Anisimov et al., 2002; Zhang et al. , 2005). Thus, they are limited to mapping permafrost probabilities, and do not account for thermal inertia (Riseborough et al. , 2008). Equilibrium (or thermal) models use a transfer function between air and ground temperatures to locate the freeze/thaw front. These models, e.g. TTOP (Wright et al. , 2003) and the Geophysical Institute Permafrost Laboratory model (GIPL: Sazonova et al. , 2004), utilize air temperature as their single meteorological input. Such models are applicable only when the system has limited complexity and the transient evolution of permafrost is negligible 
(Jafarovet al. , 2012; Walvoord and Kurylyk, 2016). Lastly, physically-based models that incorporate heat conduction with phase change are deemed the most accurate method to simulate and project the thermal regime of permafrost over different time periods (Riseboroughet al. , 2008; Jafarov et al. , 2012). The landsurface components of earth system models (ESMs), i.e. LSMs, are one example that couples heat and water transfers across soil-vegetation-atmosphere interfaces.

The current generation of LSMs provides significantly improved simulation of permafrost dynamics. Firstly, the representation of surface insulation by snow cover and soil organic matter has been enhanced, which proved to be a key regulator of atmospheric effects on permafrost thermal and hydraulic regimes (Dobinski, 2011). Improvements include multi-layer snow schemes (e.g. Chadburn et al. , 2015), enhanced frozen soil infiltration algorithms (e.g. Niu and Yang, 2006), explicit organic soil parameterization (e.g. Letts et al., 2000; Lawrence et al ., 2008; Park et al ., 2013), and adding a moss layer as the topsoil layer (e.g. Wu et al. , 2016; Melton et al. , 2019). Secondly, additional permafrost-related physical features/processes have been introduced. Examples include parameterization of hydraulic conductivity to represent the impedance of ice to water movement (e.g. Lawrence et al. , 2011; Wuet al. , 2018), including vegetation dynamics and carbonpool processes (e.g. Chadburn et al. , 2015; Melton et al. , 2019), and representing lateral taliks (Devoie et $a l ., 2019$ ) and microtopography (e.g. polygonal regions) (Aas et al. , 2019). Lastly, deeper soils have been used to better capture freeze/thaw cycles (Alexeev et al. , 2007; Nicolsky et al. , 2007). This is significant because the bottom boundary condition strongly dominates soil temperature dynamics at seasonal and longer timescales (Lawrence et al. , 2008) and shallow soil layers are insufficient to resolve the heat storage of the underlying ground. LSM configurations with shallow soil profiles were shown to overestimate the impact of climate change on permafrost (Burn and Nelson, 2006; Burkeet al. , 2020).

Despite these improvements, configuring LSMs to simulate permafrost dynamics is still challenging. The scarcity and uncertainty of permafrost observations limit the representation of spatial heterogeneity over large domains (Chadburn et al. , 2015; Obu et al. , 2019). For instance, the geothermal heat flux is needed to constrain the lower boundary of LSMs; however, no data are available for deep depths and transient conditions (Nishimura et al. , 2009) at large scales. Therefore, most modelling studies either ignore this or assume a constant value spatially and temporally. Moreover, specifying a soil profile of sufficient depth and proper discretization introduces further complications to the modelling. More effort is needed to initialize the deeper profiles due to their long thermal and hydraulic memories (Alexeev et al. , 2007) while the impact of discretization (layering) can be significant and is usually overlooked. In most modelling studies, exponentially increasing soil layer thicknesses with depth are utilized, aiming to balance computational efficiency, numerical stability and model fidelity (Sapriza-Azuri et al. , 2018; Hermoso de Mendoza et al. , 2020). The above factors affect the quality of model initialization and the subsequent simulation. Even in a 'perfect' LSM, improper initialization of state-variables could introduce significant biases in partitioning the surface energy and have a long-lasting effect on model behaviour (Chen and Dudhia, 2001; Rodellet al. , 2005).

Initialization of LSMs can be achieved using observations, despite the scale issues involved, or running model spin-up. In the former, initial conditions are based on realistic field data (e.g. soil moisture, soil temperature). However, gathering extensive datasets over large and remote (e.g. arctic/subarctic) regions and significant depths is challenging (Lamontagne-Hallé et al. , 2020). Alternatively, allowing the LSM to generate its own self-consistent initial conditions through a spin-up technique is commonly used. The spin-up can be performed by repeatedly looping a single year (e.g. CLM: Lawrenceet al. , 2008; NOAH: Shrestha and Houser, 2010; JULES: Dankerset al. , 2011) or a (de-trended) multi-year sequence (e.g.CHANGE: Park et al. , 2013), or through a long transient simulation, of the order of hundreds of years (e.g. CLASS: Sapriza-Azuri et al. , 2018). Looping over a single year is the simplest and most used approach, but may lead to biased estimates of state-variables, depending on forcing (climate) anomalies of the looped year (Rodell et al. , 2005). Similarly, spin-up using a sequence of years is prone to the same problem of bias, in addition to uncertainties associated with de-trending. On the other hand, initial conditions established by running the model for a long transient simulation is no easier. Forcing datasets of sufficiently long periods (100s of years) are rarely available, and can be obtained only through proxy records (e.g. tree rings) or paleoclimatic simulations. Proxy data generally provide mean summer temperature only, are limited spatially, and the reconstructed meteorological 
variables for LSMs simulation (e.g. precipitation, radiations) suffer from significant uncertainty, as they are typically based on a single variable. Mann et al. (1999) highlighted the non-stationarity in paleo-climatic reconstructions of tree rings during the last millennium, and hence, it is unlikely to find a long enough period of quasi-equilibrium. The simpler approach of single-year spin-up therefore seems to be the most feasible.

In LSM initialization, the relative importance of soil moisture versus temperature memory depends on several factors. Soil moisture memory was shown by Cosgrove et al. (2003) and Rodell et al. (2005) to be larger than thermal memory for shallow soil columns $(2 \mathrm{~m}$ and $3.5 \mathrm{~m})$, such that reaching a quasi-equilibrium state for moisture during spin-up requires more time than soil temperature, depending on soil characteristics. However, such conclusions may not be valid for deeper soil columns recommended for LSM simulation of permafrost, due to their larger thermal/hydraulic inertia (Sapriza-Azuri et al. , 2018; Elshamy et al. , 2020; LamontagneHallé et al. , 2020). For example, Elshamy et al. (2020) showed that soil moisture stabilized faster than soil temperature in simulations for the Mackenzie River Basin using a $51.24 \mathrm{~m}$ soil column. Further, soil moisture data can be helpful. For instance, Walker and Houser (2001) demonstrated added value from assimilating observed surface soil moisture to reduce the spin-up time of a global climate model, noting that different soil properties, e.g. soil texture, hydraulic/thermal conductivity, depth to bedrock, govern the memory of the soil system and hence the required spin-up (Rodell et al. , 2005; Shrestha and Houser, 2010; Elshamy et al. , 2020).

Thus, careful attention to the initialization/specification of soil hydraulic and thermal characteristics is critical for permafrost modelling (Takata, 2002; Lawrence et al. , 2008). Langer et al. (2013) attributed the uncertainties in modelling active layer (i.e. soil depth subjected to seasonal freeze/thaw cycles) dynamics to uncertainties in soil properties and states, especially initial soil water/ice contents. Thermal soil properties depend on moisture content and state (liquid/frozen), especially ice content. Further, the interplay between the climatic conditions of the spin-up year(s) and the initial ice-content of permafrost layers could lead to unrealistic soil thermal and hydraulic properties/states even after reaching an equilibrium state (Rodell et al. , 2005).

Our research addresses two specific objectives: (1) characterizing the impact of initial conditions on the spin-up simulation length required for model warm-up, and (2) quantifying the effect of the uncertainty of model initialization on the simulated permafrost dynamics. Point-scale experiments are configured for two permafrost sites in the Liard River basin. Different combinations of initial soil moisture content (liquid and frozen) and initial year's climate are used for model initialization. A single-year multi-cycle spin-up strategy is employed for model warm-up, based on the above discussion. The specific contributions of this research are: (1) highlighting the role of initial conditions (climate and soil moisture) for both temperature and moisture and propagating their uncertainty onto a simulation period, and (2) examining various aspects of permafrost dynamics that can be indicative of the quality of the simulation and the parametrization of ground-surface and active-layer. We consider a spectrum of cases for moisture content and its partitioning to liquid and ice, while most previous studies only considered few conditions (Rodell et al. , 2005; Shrestha and Houser, 2010; Burke et al. , 2013). Also, most previous studies selected only a few permafrost characteristics, such as ALT (e.g. Lawrence et al. , 2008; Melton et al. , 2019) or DZAA (e.g. Sapriza-Azuri et al. , 2018; Burke et al. , 2020), to evaluate dynamics (refer toTable 1 for definitions).

\section{MODELS, DATASETS, AND METHODS}

\section{MESH modelling framework}

The model utilized here is the Modélisation Environmentale Surface et Hydrologie model (MESH: Pietroniro et al., 2007). MESH is a physically-based, semi-distributed modelling system with three main components: (1) the vertical processes of moisture and heat flux land-atmosphere transfers, represented either by the Canadian Land Surface Scheme (CLASS: Verseghy, 1991, 2000) or the Soil, Vegetation and Snow scheme (SVS: Husain et al. , 2016), (2) the lateral movement of surface (overland) and subsurface (interflow) flows 
to the drainage system, represented by the WATROF (Soulis et al. , 2000) or PDMROF (Mekonnen et al. , 2014) algorithms, (3) the hydrological routing between river-network grids, represented by the WATROUTE component of the WATFLOOD hydrologic model (Kouwen et al. , 1993b).

To represent the landscape, MESH is based on a model grid that is subdivided into grouped response units (GRU: Kouwen et al. , 1993a) based on land cover, soil type, slope/aspect. Water and energy fluxes are computed at the tile-level (GRUs mapped onto grids) and then aggregated to the grid-scale using weighted averaging based on the areal fractions of GRUs in each grid. MESH runs at a sub-daily time-step forced by seven meteorological variables, namely air temperature, barometric pressure, incoming longwave and shortwave radiation, precipitation, specific humidity, and wind speed. MESH has been widely utilized to simulate land surface-hydrology processes in cold regions (e.g. Razavi et al. , 2010; Haghnegahdar et al. , 2014; Davison et al. , 2016; Yassin et al. , 2017; Elshamyet al. , 2020).

In this study, CLASS is used as the underlying land surface model. CLASS simulates the coupled water and energy balances for a user-defined soil layering that is generalized across the modelled watershed. Above ground, CLASS encompasses four plant functional types, needle-leaf forest, broadleaf forest, grassland and cropland. Below ground, soil parameters (defined by Sand, Clay, and Organic matter percentages) implicitly link soil thermal (i.e . heat capacity and thermal conductivity), and soil hydraulic properties (e.g . porosity and saturated hydraulic conductivity); the latter being defined using Cosbyet al. (1984). During runtime, each soil layer's temperature and moisture content can evolve and update the associated thermal properties. This occurs down to the depth of bedrock, or the soil permeable depth (SDEP), below which no moisture migration is allowed; only heat can transfer vertically between the soil layers in this region.

CLASS incorporates the Neumann-type boundary condition at the bottom of the soil column (constant geothermal flow) by which the user can replicate the presence of an upward geothermal flux. Flux exchanges with the atmosphere determine the upper boundary condition through the solution of the surface energy balance. Initial conditions include prognostic variables for each soil layer, such as temperature and volumetric moisture content, in addition to other surface state variables.

Fully organic soils can be handled by CLASS using three predefined organic peat types (i.e . fibric, hemic and sapric) based on the work of Letts et al. (2000). Compared to mineral soil, peats have higher porosities $(0.93,0.88,0.83$ for the three sub-types respectively compared to 0.49 for clay), higher retention capacity $(0.275,0.62,0.705)$, higher residual water content $(0.04,0.15,0.22)$, higher heat capacity $\left(2.5 \times 10^{6} \mathrm{Jm}^{-3} \mathrm{~K}^{-1}\right)$, and lower thermal conductivity $\left(0.25 \mathrm{Wm}^{-1} \mathrm{~K}^{-1}\right)$ than mineral soils. Thermal properties are taken to be the same for all organic sub-types. Further details are provided in Verseghy (2012).

MESH/CLASS is usually run at a 30-min time-step, and different permafrost characteristics can be output from the simulated temperature profiles. For the present study, the following related aspects of permafrost are considered: temperature envelopes (Tmax and Tmin), mean annual ground temperature profile at the top of the permafrost (MAGTp), active layer thickness (ALT), depth of the zero-annual amplitude point (DZAA), depth to the base of permafrost (BP), thermal offset, surface offset, and date of maximum thaw (ALT-DOY) (see Fig. 1 andTable 1 ).

\section{Possible Position of Fig. 1 .}

\section{Possible Position of Table 1 .}

\section{Study area and data}

The experimental sites selected for this study are near the outlet of the Liard River Basin, Northwest Territories, Canada (Fig. 2 ). The area is located along the divide between sporadic and discontinuous permafrost regions based on the permafrost Map of Canada (Hegginbottomet al ., 1995). More than half of the basin is underlain by sporadic permafrost, mainly in the south, discontinuous permafrost underlays the northern third of the basin, and the rest of the basin is underlain by patchy permafrost (Fig. 2 ). The climate is characterized as subarctic according to the Köppen-Geiger classification (Peel et al. , 2007). The 
basin is underlain by warm-permafrost $\left(\right.$ near $0^{\circ} \mathrm{C}$ ), where a rapid reduction in the extent of permafrost in the Canadian sub-arctic has been observed due to climate change (DeBeer et al. , 2016; Connon et al., 2018). The Liard River basin plays a central role in the sub-continental Makenzie River Basin's hydrology, as it has the highest runoff coefficient and contributes the largest mean annual flow to the Mackenzie River at the outlet (Woo, 2012).

The availability of soil temperature data is limited to a few experimental sites (e.g.Scotty-Creek (Quinton and Marsh, 1999)), and measurements made during/after the construction of infrastructure for maintenance and monitoring purposes (e.g. Norman Wells-Zama pipeline (Smithet al. , 2004); Yukon Alaska Highway (Oldenborger et al. , 2015)). In this study, two representative permafrost sites were selected due to the availability of soil temperature data at multiple depths and corresponding borehole logs (Fig. 3 ). These were Jean Marie Creek (borehole 85-12B), underlain by sporadic permafrost, and Wrigley Highway (borehole 99TC03), underlain by discontinuous permafrost (Table 2 ), initially installed to monitor the Norman WellsZama pipeline's impact on permafrost. Several Geological Survey of Canada (GSC) reports have been used to extract the thermal and geological data for the current study (Smithet al. ,2004, 2009, 2010, 2016; Ednie et al. , 2012; Chartrand et al. , 2014).

The Jean Marie Creek (JMC) site is dominated by boreal forest (mainly needleleaf) and scattered ericaceous shrubs on peat plateaux where permafrost is warm (Mean Annual Ground Temperature (MAGT) of $-0.1^{\circ} \mathrm{C}$ ) and of limited thickness $(\sim 4 \mathrm{~m})$ and the active layer is shallow $(\sim 1.5 \mathrm{~m})$. The data span 1986 to 2000, with no records available in the $21^{\text {st }}$ century. The Wrigley Highway $(\mathrm{WH})$ site is dominated by shrubs with a small black spruce thicket and moss. At this site, permafrost is also warm (MAGT of $-0.2{ }^{\circ} \mathrm{C}$ ) but has a larger thickness $(\sim 10 \mathrm{~m})$ than JMC while the active layer is slightly deeper $(\sim 2 \mathrm{~m})$. Since the two sites are relatively close ( $\sim 60 \mathrm{~km}$ apart), they have similar climatic conditions with an average annual daily air temperature over the $1979-2017$ period of $-2.5^{\circ} \mathrm{C}$ and $-1.9^{\circ} \mathrm{C}$, and average annual precipitation of $430 \mathrm{~mm} \mathrm{yr}^{-1}$ and 420 $\mathrm{mm} \mathrm{yr}^{-1}$ for the JMC and $\mathrm{WH}$ sites respectively.

MESH requires seven climatic variables at a sub-daily resolution to drive CLASS, as mentioned in Section 2.1. Selection of a forcing dataset is constrained by the quality of atmospheric data and the availability of permafrost data, which spans 1986 - 2000 for JMC and 2007-2015 for WH (Table 2 ). A few forcing datasets start prior to the 1980s such as WFD (WATer and global CHange (WATCH) Forcing Data) (Weedon et al. , 2011), Princeton (Sheffield et al. , 2006), and WFDEI (WFD with the ERA-Interim analysis) (Weedon et al. , 2014). However, the WFD and Princeton datasets end in 2001 and 2012 respectively. The combined Global Environmental Model (GEM; Coteet al. , 1998) atmospheric forecasts and the Canadian Precipitation Analysis (CaPA; Mahfouf et al. , 2007) have been found to compare well with ground observations (Wong et al. , 2017), but GEM-CaPA is not available prior to 2002. Since the WFDEI dataset provides reasonable estimates of climate fields, as shown by Wong et al. (2017) for precipitation, and is available from 1979, covering the duration of the permafrost records, WFDEI is used for driving CLASS for the period 1979-2016, at 3-hour resolution.

\section{Possible Position of Fig. 2.}

Possible Position of Table 2 .

Possible Position of Fig. 3 .

\section{Model configuration}

The JMC and WH models were configured using the approach of Elshamy et al . (2020), where MESH was applied to three permafrost sites along the Mackenzie River valley. Three families of model parameters were identified: soil column configuration, soil texture, and surface canopy. Firstly, for soil layering we employed the scheme of Elshamy et al. (2020) for both sites. This extends to $51.24 \mathrm{~m}$ depth and has a fine discretization (9 layers) for the upper 2 meters of the soil, in line with the observed ALT for both sites (Table 3 ). No-heat flux was used as the lower boundary condition of the soil column. The effects 
of the lower boundary condition were assumed negligible because of its limited impact on the simulated soil temperatures for centennial timescale simulation, as several studies reported (Nicolsky et al. , 2007; Lawrenceet al. , 2008; Hermoso de Mendoza et al. , 2020). Regarding SDEP (depth to the bedrock), we used the gridded bedrock depth dataset by Keshav et al. (2019b) to identify the mean value of SDEP for the two sites: $7.00 \mathrm{~m}$ and $10.77 \mathrm{~m}$ for JMC and WH, respectively. SDEP is an important parameter that plays a pivotal role in the simulation of permafrost as it alters the thermal regime's properties (conduction and storage) and the system's water storage/drainage (see (Elshamy et al. , 2020) for further discussion).

\section{Possible Position of Table 3 .}

The second set of parameters are soil texture parameters, which are used in CLASS to parameterize the thermal and hydraulic properties; thus, they strongly influence water and heat storage and movement/conduction. Organic soils are characterized by large heat and moisture capacities that regulate the effects of atmosphere on permafrost around the year (Dobinski, 2011). Therefore, we focused on their representation in our model setups. However, the available soil texture data are insufficient to configure a deep model profile. Soil maps such as Cartographic 1:1000,000 Soil Landscapes of Canada (SLC) v2.2 (Centre for Land and Biological Resources Research, 1996) and its gridded product (Keshavet al., 2019a) only offer data on the spatial characteristics of soil, with no mention of variation with depth. The Global Soil Dataset for Earth system models (GSDE: Wei et al. , 2014) provides gridded texture information for 8 layers but only to a depth of $2.3 \mathrm{~m}$. Even though the available borehole logs around (and at) the two sites provide valuable geotechnical data, they lack necessary information on the organic matter content and its thermal and hydraulic properties (the logs provide a qualitative description of the soil components following the USDA classification). Therefore, the most feasible approach was to test different configurations of the soil organic matter, which can be parametrized either as Fully Organic Soil (FOS) or as Mineral Soil with Organic content (MSO). CLASS uses organic matter content within the mineral soil to update only the thermal properties (heat capacity and thermal conductivity), similar to CLM 4.5 (Olesonet al. , 2013). We configured the soil column of JMC using the FOS configuration for the upper $1.46 \mathrm{~m}$ (20 cm fibric $+40 \mathrm{~cm}$ hemic $+86 \mathrm{~cm}$ sapric), and the rest of the soil column as silt loam with high organic content (50\% organic content) - full details are given in Elshamyet al. (2020). For the WH site, we configured the upper $0.81 \mathrm{~m}$ using the MSO approach (silt loam with 50 $60 \%$ organic content), and the rest of the column as mineral $(3.50 \mathrm{~m}$ sand/silt fine-grained, the rest as silty

clay). The MSO configuration was selected for WH site based on the outcomes of benchmarking simulations that yielded better results (i.e. ALT and temperature envelopes) compared to the FOS approach.

The last group of model parameters are those used to parametrize surface canopy conditions. We used the CLASS manual (Verseghy, 2012) to identify the associated parameter values for the two sites, given that JMC is dominated by boreal forest, while evergreen shrubs cover the WH site. Each setup is configured with a single GRU using the single MESH column.

\section{Experimental design}

The setups for the two permafrost sites were designed to explore the influence of the uncertain initial model states on the spin-up length (i.e. length required for appropriate model warm-up) and its extended effect on permafrost during a subsequent simulation period. We utilized a single-year spin-up strategy for a maximum of 2000 annual cycles, which is compatible with the available literature on LSM permafrost modelling (Dankers et al. , 2011; Burke et al. , 2013; Elshamy et al. , 2020). As discussed above, the single-year approach is the simplest and most commonly employed method for initializing LSMs (e.g. Rodell et al. , 2005; Nishimuraet al. , 2009; Burke et al. , 2013). However, the resulting state-variables may suffer from an accumulated bias depending on the spin-up year's climate (Rodell et al. , 2005). Likewise, the other available spin-up techniques (e.g. using a (detrended) sequence of years and long transient simulation) do not resolve this issue (seeSection 1 ).

As a single year of forcing is cycled, a complete spin-up would theoretically be achieved if the model states at year $m$ are identical to year $m+1$. However, achieving a highly precise state equilibrium is not always 
necessary or feasible, especially for global-scale simulations due to the immense computational cost (Rodell et al. , 2005). We focused on soil temperature profiles and soil moisture (both frozen and liquid) profiles for the stabilization analysis. Previous studies considered either soil temperature (e.g. Burke et al. , 2013; Elshamy et al. , 2020) or total (unpartitioned) soil moisture (e.g. Rodellet al. , 2005; de Goncalves et al. , 2006; Shrestha and Houser, 2010). We considered a tolerance of $0.1 \mathrm{deg} C$ for temperature states (the same accuracy of permafrost thermal measurements) and $0.01 \mathrm{~m}^{3} \mathrm{~m}^{-3}$ for liquid and frozen water states of each soil layer. The stabilization length (i.e. number of spin-up cycles) was defined from when the differences in selected states are less than the identified thresholds, and we used the last timestep of each cycle in the stabilization analysis. There is no consensus among LSMs communities on defining the convergence criteria for adequate model initialization (Yang et al. , 1995). For example, Burke et al. (2013) considered a successful initialization of JULES had been achieved when the variation of soil temperature during spin-up is less than $0.2 \mathrm{deg}$ C. Employing high thresholds could lead to biased state-variables, while lower thresholds are not feasible for large-scale applications due to their extensive computational cost.

To account for the impact of the initial year's climate, we selected five climatic conditions based on the total annual precipitation and mean annual air temperature, as per the suggestion by Sapriza-Azuriet al. (2018). We used the WFDEI dataset to identify these, namely wet year (high precipitation), dry year (low precipitation), cold year (low temperature), warm year (high temperature), and an average year (for both precipitation and temperature). Table 4summarizes the climate conditions for the two permafrost sites using a hydrological year (i.e. Oct $1^{\text {st }}$ to Sep $30^{\text {th }}$ ).

Similarly, to account for the effects of initial soil moisture content, we considered 21 different uniform cases covering the spectrum of soil water content (water and ice content), as summarized in Fig. 4. These are nonequilibrium states but address the subjectivity of initial soil water content selection/configuration in previous studies. For instance, Rodellet al. (2005) and Shrestha and Houser (2010) defined initial soil moisture as $70 \%$ and $10 \%$ of saturation for wet and dry conditions, respectively, unlike Cosgrove et al. (2003) and de Goncalveset al. (2006) who quantified these conditions as $100 \%$ and $0 \%$ saturation, respectively. The two relevant permafrost studies by Sapriza-Azuri et al. (2018) and Elshamy et al. (2020), which utilized the same model as here (MESH/CLASS), did not address this issue. For the dry experiment, with zero saturation for liquid water content, CLASS constrains the residual water content at a value of $4 \%$ for mineral soil (MSO configurations). For the FOS configurations, the residual liquid content (or retention capacity) is a function of the organic soil sub-type and varies between $4 \%$ and $22 \%$, as mentioned inSection 2.1 .

All models were set with the same initial condition for soil temperature, defined as 0degC along the whole profile, except for the bottom temperature, which was extrapolated from the available temperature records following Elshamy et al.(2020), specified as 0.8degC and 0.5degC for the JMC and WH sites, respectively. We assumed uniform initial profiles for soil temperature and moisture contents due to the simplicity of this approach, and to avoid subjectivity in defining a non-uniform profile, especially for temperature. However, the model is shown to rapidly adjust to self-consistent states. Therefore, each site has a total of $1051-\mathrm{D}$ scenarios $\{5$ climate conditions x 21 soil moisture conditions $\}$, covering distinctive climate and soil moisture conditions. Subsequently, we ran all scenarios for a simulation period of 1979-2016 to assess the impact of uncertainty in initial conditions on various aspects (seeFig. $\mathbf{1}$ and Table $\mathbf{1}$ ) of permafrost dynamics. The analysis incorporated quantitative assessment of simulated permafrost in terms of root mean square error (RMSE) for the temperature profiles and ALT error (Bias) over the same period, whenever there were observations.

\section{Possible Position of Table 4.}

Possible Position of Fig. 4. 


\section{RESULTS AND DISCUSSION}

\section{Model initialization}

The minimum number of spin-up cycles needed to reach stabilization for soil temperature and moisture content under different initial conditions is summarized in Fig. 5 . Several points can be observed:

- (subplot A) initial soil moisture controls spin-up length for temperature regardless of the spin-up year's climate. Experiments initialized by a warm climate showed less dependency on the initial soil moisture.

- (subplot A) the initial year's climate plays a central role in determining spin-up length for liquid soil water content. The dry year requires the most prolonged spin-up to achieve stabilization.

- (subplot A) both the initial year's climate and initial soil moisture are comparably important to control the convergence rate of frozen soil water content.

- (subplot B) the initial year's climate influences the spin-up needed for soil temperature. All dry and wet experiments stabilize after less than 200 cycles, unlike other climate conditions that may need 100-1000 cycles, based on the initial soil moisture.

- (subplot B) the initial climate condition is the primary driver of liquid water content convergence, similar to the JMC site.

- (subplot B) initial climate and initial soil moisture influence the required spin-up to attain steady-state frozen soil water content, with a more substantial influence of the initial climate than the JMC site.

Both sites showed a noticeably larger thermal memory compared to the hydraulic one, as found by Elshamy et al. (2020). It worth noting that the WH site did not form permafrost under warm conditions (i.e. soil layers temperatures $>0 \operatorname{deg} C$ ), as discussed later in this section.Possible Position of Fig. 5 .

The behaviour across soil layers varies as the spinning-up process continues (Fig. 6 ), which is attributed to the function of each group of layers in water and energy exchange, including the root zone extent, the percentage of organic matter, the depth of organic soil (denoted ODEP thereafter), SDEP, and most importantly, the memory of the system (Taylor et al. , 2006). In general, temperature profiles change rapidly within the first few cycles and then stabilize with no significant changes after 1000 cycles, or less, depending on the initial water content and the climate of the spin-up year. After stabilization, most simulations showed further minor fluctuations, which can be attributed to model numerical instabilities, but their impact on the simulations is minimal. Soil moisture profiles depict the same behaviour with a relatively higher variation for the few first cycles. For example, Fig. 6A shows the pattern of change of each soil layer's temperature, water content, and ice content over the spin-up cycles at the JMC site, under dry spin-up year climate conditions, and relatively dry initial soil content (Exp 7: 25\% liquid $+25 \%$ Ice). The fully organic soil layers (i.e . layer 1:8) exhibited a sharp change within the first 50 cycles, followed by relatively insignificant variations for soil temperature and water contents. The lower soil layers down to SDEP (i.e . layers 9:14) had considerable temperature variations. In contrast, only the layers at the interfaces at ODEP and SDEP displayed significant oscillations in soil water and frozen content, due to the sudden change in soil properties that led to numerical artefacts - SDEP was not nudged/relocated to the nearest layer's boundary in the current study. Soil layers below SDEP (i.e . layers 15:25) showed a diminishing pattern of variations with depth, with no variations at the lower boundary where the geothermal flux is set to zero.

Fig. 6B presents the initialization results at the WH site under wet spin-up climate conditions and relatively dry soil conditions (Exp 17: 12.5\% liquid + 12.5\% Ice). The MSO layers (i.e . layer 1:6) stabilized after a few cycles $(\sim 10)$ for temperature and water content, with negligible variations afterwards. As for the JMC site, lower soil layers down to the $\operatorname{SDEP}$ (i.e . layers 7:16) showed the main fluctuations for temperature (stabilizes after 100 cycles), while the interfaces at SDEP and ODEP drive the variations for liquid and frozen water contents. Another example for the WH site is provided in Fig. 6C , which shows the spin-up convergence under average climatic conditions and high initial ice content (Exp 10: 0\% liquid $+75 \%$ Ice), noting that this experiment did not form/initialize permafrost at the end of spin-up. This is mainly attributed to the characteristics of the spinning year's climate condition (i.e. average), rather than the specified initial soil 
moisture - all simulations under average and wet climate conditions did not form permafrost (discussed later in this section).

Fig. 7 summarizes the required spin-up cycles needed by the three state variables to reach equilibrium simultaneously for each climate year and each initial soil storage scenario. The two sites required 200-1000 spin-up cycles to perform an appropriate model initialization, depending on the spin-up year's climate, as shown inFig. 7A . However, employing average and warm climatic conditions at WH site led to faster stabilization $(<200$ cycles $)$ without forming permafrost. Initializing the two sites under wet climate resulted in the shortest spin-up needed to form permafrost, compared to the other climatic conditions. On the other hand, grouping the initialization results regarding initial soil storage provides further insight into the impact of saturation level and the associated partitioning into liquid and frozen contents ( Fig. 7B ). Extreme saturation conditions, i.e. $100 \%, 75 \%$ and $0 \%$, yielded the longest required spin-up cycles among all configurations at both sites. Average initial total soil moisture, i.e. $50 \%$ and $25 \%$, required relatively shorter spin-up to stabilize, with best performance for $25 \%$ total soil water content that corresponds to field capacity condition. Further, Exp 16 (25\% liquid + 0\% Ice) and Exp 18 (18.75\% liquid + 6.25\% Ice) showed the minimal spin-up needed to initialize and form permafrost at the two sites under different climatic conditions. Note that the partitioning of liquid and frozen contents played a central role in the spin-up rather than the overall degree of saturation, as depicted in the first five experiments $(100 \%$ saturation with different partitioning).

As mentioned earlier, the annual average air temperature and annual total precipitation were utilized to distinguish the various climate conditions (Sapriza-Azuri et al. , 2018). However, employing such mean/total measures could be insufficient and misleading, ending up in an unrealistic simulation. Fig. 8 shows the daily-evolution of air temperature and 'cumulative' precipitation at the WH site. Our selected 'average' year (i.e . based on annual total/mean) exhibits wet winter precipitation, while the fall's air temperature included some relatively warm events. Further, the 'average' year had a cold-dry winter and spring, which led to relatively lower accumulation of snow on the ground. Likewise, the representative warm year recorded the lowest air temperature at the onset of winter and spring, coincident with relatively the wet- and dry-year conditions, respectively. Since WH site was configured without heavy organic soil (i.e. peat) and the surface vegetation was shrub canopy, the presence of sufficient snow is the major element for buffering/regulating the impact of external forcing on soil layers, and hence, the formation of permafrost (Dobinski, 2011). Another example can be seen in the representative 'wet-year' having the lowest precipitation volume for half of the year, coincident with the selected warm-year condition at the same period. Such intra-annual variations could affect the initializations drastically, as for the case of the wet year that was a combination of dry and warm conditions in winter and fall, disallowing any insulation by snow and providing extra heat flux at the vegetation-soil interface.

It worth noting that for the case of WH, our selected spin-up year with 'average' climate is the second coldest year among the five years (seeTable 4 ), with an annual average air temperature of $-2.2 \mathrm{degC}$ did not form permafrost, while the other warmer years, i.e.designated as Wet $(-1.14 \mathrm{deg} C)$ and Dry $(-1.19 \mathrm{degC})$, have successfully formed permafrost after a longer spinning effort. Fig. 9 compares the daily evolution of the external forcings (i.e. precipitation, air temperature and accumulated snow depth) and the associated response of the soil state-variables (i.e. soil temperature and moisture contents) under average climate (left panel) and cold climate (right panel) for the same initial moisture condition (Exp 1: $100 \%$ liquid $+0 \%$ Ice) at the WH site. The peculiarity of the last week (or ten days) of September is the main reason for not forming permafrost under the 'average' year. In detail, the air temperature rose $\left({ }^{\sim} 10 \mathrm{deg} C\right)$ and was accompanied by a rainfall event $\left({ }^{\sim} 20 \mathrm{~mm}\right)$, which seeped down to the soil system and warmed it up - liquid content increased and hence the system's thermal conductivity. Subsequently, the warming propagates for few spin-up cycles until the system reaches a self-consistent state. The spin-up needed to attain stabilization (without forming permanent ice) is controlled by the specified initial moisture conditions, which vary between 10 and 200 cycles for both the average and warm initial climates for WH setup.

Possible Position of Fig. 6 . 


\section{Possible Position of Fig. 7 .}

Possible Position of Fig. 8 .

Possible Position of Fig. 9 .

\section{Uncertainty propagation}

In this section, we propagate the uncertainty of initialized model states (at the end of spin-up) through the simulation period and quantify the resulting uncertainty using two error metrics describing the simulation quality. We also focus on the temporal variation of different simulated aspects of permafrost. Fig. 10 shows the envelopes of soil temperature, liquid content, and frozen content profiles at the end of spin-up for the two sites, from all initialization experiments. Given that the presented results correspond to the last day of the spin-up "Sep $30^{\text {th" }}$ ", the following points can be noted:

- Temperature (subplots A and B): JMC site has a relatively constrained temperature envelope near the surface $(3.5 \operatorname{deg}$ ) , while the biggest variability is observed at the middle of ODEP (5.5degC) with a diminishing envelope downward to SDEP (2.5degC). In contrast, the ODEP-SDEP portion of the WH setup shows the highest variability, varying by $5 \mathrm{degC}$ at ODEP and the range reduces to $1.5 \mathrm{deg} \mathrm{C}$ at SDEP. All JMC experiments were capable of producing permafrost, which is not the case for the WH setup, as $40 \%$ of its experiments failed to develop permafrost after an exhaustive spin-up.

- Temperature (subplots A and B): the impact of initial climate condition is clear on the simulated temperature at both sites, as shown by the clustered (well-defined) profiles. Initial soil moisture partitioning exerts additional influence on simulated temperature as shown in the scattered profiles of the cold year of JMC site - moisture partitioning has a limited impact on WH experiments.

- Liquid water content (subplot C): The upper $0.2 \mathrm{~m}$ of JMC experiments (i.e. hemic peat (porosity = 0.93)) has the highest variability of $0.24 \mathrm{~m}^{3} \mathrm{~m}^{-3}$ with a diminishing envelope downward to ODEP. On the other hand, the whole soil column of WH site exhibits a wider range of variability for the simulated liquid soil water profile $\left(0.10-0.15 \mathrm{~m}^{3} \mathrm{~m}^{-3}\right)$. Still, the surface layer(s) at WH retained less water, due to the lower soil porosity $(0.45)$. At the bedrock interface (SDEP), there is a noticeable fluctuation in the simulated liquid water content for the two setups.

- Liquid water content (subplot C): the initial year's climate dominates the amount of stored water in the hemic layer of JMC site, followed by a negligible impact for the rest of the soil column. Average and warm years provide the wettest moisture condition for the SDEP portion of WH. The other climate conditions yield the driest moisture condition down to SDEP, except the wet year that provides high liquid content for the upper $2 \mathrm{~m}$. The impact of initial soil storage (and the partitioning) is negligible as experiments with the same climate condition are distinctively clustered.

- Frozen water content (subplot D): major variability has been recorded for frozen compared to liquid water content. The two sites show a similar response across ODEP-SDEP portion (vary by 0.40 $\mathrm{m}^{3} \mathrm{~m}^{-3}$ ), accompanied by significant differences above ODEP. In detail, WH simulations produced warmer soil temperature (as shown in subplot $\mathrm{A}$ and $\mathrm{B}$ ) down to $1.5-2 \mathrm{~m}(\mathrm{ODEP}=0.81 \mathrm{~m}$ ), while the corresponding depth for JMC case is located at $0.8 \mathrm{~m}$ (within ODEP region of $1.46 \mathrm{~m}$ ). Such uncertainty in the frozen water content (entire profile of each site) could propagate into the simulation and produce divergent results.

- Frozen water content (subplot D): the two sites did not show any obvious dependency on initial climate - except warm/average conditions of WH that did not generate frozen soil, and cold condition in JMC that formed the largest frozen content at ODEP interface. Experiments with different initial moisture conditions and the same climate condition are spread within the whole envelope. This suggests a stronger influence of initial water content partitioning on the formed ice than the initial climate.Possible Position of Fig. 10 .

Fig. 11 shows the impact of spin-up conditions on two performance metrics of the simulated permafrost, noting that the length of available record varies between the two sites. The bias in ALT (eALT) is insensitive 
to the climate condition of the spin-up year for the JMC site -ALT is overestimated by $0.3 \mathrm{~m}$, except for the cooler condition, which underestimates ALT by $0.3 \mathrm{~m}$ (see Fig. 11 ). Initialization with a dry soil (i.e. Exp 21: 0\% Water + 0\% Ice) caused an apparent overestimation of ALT of the order of $0.8-1.2 \mathrm{~m}$. On the other hand, the simulated ALT at the WH site exhibits a general tendency to underestimation, by $0.2-0.8 \mathrm{~m}$, underlining partially the insufficient insulation provided by the MSO. It is worth noting that the experiments that failed to establish permafrost during the spin-up procedure developed it within the simulation period. The average- and wet-based experiments overestimate ALT by $0.25 \mathrm{~m}$, unlike the rest of the experiments that underestimate it by a similar magnitude (see Fig. 11 ). Experiments with the fully dry soil condition (i.e. Exp 21) did not show any differences between sites, which can be associated with the role of soil-texture and land-cover parameterizations.

The second performance metric used is the mean RMSE of the annual temperature envelopes (see Fig. 11 ) - calculated for the entire profile over every year, whenever observations are available. Since the depths of observations are not the same as used to configure the soil column, the RMSE is calculated by interpolating the simulated temperature envelope to the observation depths using the nearest neighbour method. While for JMC, ALT is overestimated with higher RMSE of the annual temperature envelope, varying by $\sim 2.0^{\circ} \mathrm{C}$ at each simulation year, the WH setup, which tends to underestimate ALT, provides more accurate annual envelopes with a range of variability around $0.5^{\circ} \mathrm{C}$. Fig. 12 shows the annual RMSE of Tmax and Tmin at the two sites. Again, the two sites tend to have cooler Tmin envelopes than observed (not shown), resulting in higher errors for the cold part of the mean temperature profile. Regarding the annual maximum temperatures at JMC, most simulations produce the warm envelope with lower RMSE, with an upper limit of the error of $+1.5^{\circ} \mathrm{C}$. The annual minimum envelope at the $\mathrm{WH}$ site shows the opposite behaviour as the mean of simulations is closer to the upper limit of variability for all the experiments, with a narrower magnitude compared to the JMC site. These two examples highlight how the uncertainty inherent in the initialization of LSM can change the quality of the simulated soil temperature envelope.

\section{Possible Position of Fig. 11 .}

\section{Possible Position of Fig. 12 .}

Fig. 13A summarizes the simulated MAGTp calculated at the top of permafrost (bottom of the active layer). JMC showed cooler MAGTp compared to WH. The impact of the initial soil moisture is not identical among different climate conditions at the two sites, underscoring the influence of the driving climate on MAGTp profiles and the propagation of its uncertainty. Cold conditions at JMC tend to produce cooler permafrost (cooler MAGTp); a similar observation can be noticed for cold and dry climates at the WH site. The annual range of uncertainty of MAGTp is ${ }^{\sim}-2.5^{\circ} \mathrm{C}$ at both sites.

Analyzing the offset effects (i.e. thermal and surface) reveals the high impact of the thermal offset occurring within the active layer. Initial soil moisture and climate conditions affect the cooling/heating flux to the permafrost, ranging between $2-3^{\circ} \mathrm{C}$ annually among all the experiments at the two sites. On the other hand, the 'surface offset' above ground due to the accumulated snow in winter and the standing canopy in summer shows insensitivity to the initialization condition (i.e. initial moisture content) with an insignificant range of variability among all tests (figures not shown).

The day of maximum thaw (ALT-DOY) is among the most sensitive variables to the model's identified initial conditions. It is calculated from the maximum daily temperature envelopes and is indicative of the thawing/freezing cycle. Fig. 13B shows the time series of ALT-DOY for the two modelled sites. On average, the propagated uncertainty range in the thaw date is two to four weeks, moving between August and October at the two sites, except for WH's experiments with dry and average conditions. These configurations showed a large discrepancy at the beginning of simulation up to the beginning of the 2000s and then yielded a similar range of uncertainty.

DZAA (refer to Table $\mathbf{1}$ for definition) is another facet of permafrost that sheds light upon the suitability of the selected soil column depth. It should lie well within the configured depth (e.g . Sapriza-Azuri et al. , 2018), can be used as an auxiliary variable to quantitively assess the simulation (e.g . Elshamy et al. , 
2020), or can be used implicitly to identify the presence of permafrost by calculating its corresponding soil temperature (TZAA) (Burke et al. , 2020). In the current study, we assessed the variability in DZAA during the simulation period in response to the initialization. Fig. 13Cpresents DZAA for the whole simulation period (i.e . 1980 - 2016) at the two sites. In general, JMC and WH depict a different response to the spin-up year with average and warm conditions compatible with the simulated ALT and the mean RMSE for the same conditions (seeFig. 11 and Fig. 12 ). The two sites indicate considerable uncertainty to the initial soil storage, with a minor impact of the initial climate condition. In detail, for the JMC site, experiments forced by average and warm climate conditions of the initial year depict an inconsistency of the simulated DZAA, which could reach two-fold (from 6 to $16 \mathrm{~m}$ ) for tests with intermediate to low initial soil storages (Exps: 11-21). Similar behaviour with higher intensity (four- to-five-fold) is presented at WH for cold and dry initial soil water content cases. The two experiments showed that the selected soil column depth $(51.24 \mathrm{~m})$ is adequate and suitable to initialize and simulate permafrost for a 38-year period.

Another vital characteristic of permafrost that does not always receive proper attention in the LSMs/ESMs simulations is the permafrost thickness or the depth to the base of permafrost (PB). Modelling PB is only possible in regions with shallow permafrost where it falls within the configured soil depth. PB can be obtained directly from borehole measurements, or from the temperature profile when the thermal probes penetrate all through to the base; derived as the distance between the two (i.e. upper and lower) $0^{\circ} \mathrm{C}$ isotherms. Alternatively, $\mathrm{PB}$ is acquired by extrapolating the temperature envelope using the temperature gradient (i.e.geothermal flux). Besides, PB and MAGTp are among the major factors that describe permafrost's local and regional conditions and are mainly utilized in engineering design (Wu et al. , 2010), and enhance the simulation/quantification of the global carbon cycle, as being a deep carbon pool (Schuur et al. , 2008). Fig. 13D presents the temporal evolution of the depth to the base of permafrost at the two sites. PB's general behaviour is comparable to DZAA (Fig. 13C ), with less variability over time, as expected. The simulated permafrost base shows a slight tendency to deepen over time at the two sites under each initializing condition. In other words, the simulations underlined the significant influence of initial soil storage rather than initial climate conditions on the depth to the base of permafrost. Experiments with low initial storage (Exps: 16-21) have the shallowest permafrost base, compared to the intermediate and high values used for initializing soil storage. The simulated PB at the two sites could vary by up to four- to five-fold among all the initialization experiments.

\section{Possible Position of Fig. 13 .}

\section{SUMMARY AND CONCLUSIONS}

The commonly applied spin-up method for land surface model (LSM) initialization was assessed, under different climate conditions for the spin-up year and using various initial soil moisture states, at a sporadic and a discontinuous permafrost site in the Liard River Basin in Canada. The single-year spin-up technique for 2000 cycles was evaluated to initialize and simulate permafrost dynamics using 1D MESH/CLASS model simulations. The study highlighted that employing a deep soil configuration in LSMs requires adequate attention to the initial states as these play a central role in the rate of spin-up stabilization and the fidelity of subsequent simulation. The initial water storage and its partitioning into liquid and frozen contents can affect the system hydraulic and thermal memories, and consequently, the capability of initializing permafrost in LSMs/ESMs. Previous studies focused on identifying appropriate initial soil saturation for model initialization, which is shown in this study to be insufficient due to the interplay between soil liquid and frozen contents on the quality of spin-up. For instance, five different partitioning conditions of a fully saturated soil column required different spin-up effort to attain stable state-variables. Our analysis shows that model spin-ups based on a back-to-back repetition of 200-1000 cycles could be appropriate for initializing soil temperature and water content profiles under different climate conditions, moisture conditions, and model configurations. Such a conclusion can be extendable to other LSMs/ESMs, given the immense computational resources needed for large-scale applications. 
Further, initializing the soil column with near field capacity conditions (25\% saturation: $25 \%$ liquid $+0 \%$ Ice, or as $18.75 \%$ liquid $+6.25 \%$ Ice) required minimal spin-up effort to form permafrost under different climates. Similarly, the wet climate spin-up year led to the shortest spin-up to initialize permafrost in the deep soil column. On the other hand, utilizing only the annual totals/averages while identifying the initial year's climate condition could be insufficient and leads to non-representative transient conditions. The selection of the initial year's climate is challenging as the interplay between the external forcing (i.e. precipitation and air temperature) dominantly control permafrost initialization behaviour in LSM. Considering additional statistical measures is advisable, especially those measuring the seasonal patterns (monthly/seasonal statistics) or using more comprehensive measures such as the coefficient of variation along with the annual totals/averages. Further, it is suggested to avoid any peculiarities around the beginning and the end of the spin-up year to ensure successful initialization of permafrost. The large variations observed in the initialization experiments necessitate assessing the associated impact of the uncertain initial conditions on the simulation.

We analyzed the effect of initialization uncertainty on various soil states at the end of spin-up. The portion of the soil column between the permeable depth (SDEP) and the organic depth (ODEP) showed a high range of variability for frozen water content and soil temperature to uncertainties of model initialization for both setups. Below SDEP, temperature profiles showed a decaying sensitivity to the initial condition perturbation, with no impact at the bottom of the soil column. The magnitude of variability for soil temperature was $4-5^{\circ} \mathrm{C}$ for the permeable part of the soil column, and $0.4 \mathrm{~m}^{3} \mathrm{~m}^{-3}$ for the frozen water content down to SDEP. Layers at the ODEP and SDEP interfaces showed significant oscillations in soil liquid and frozen contents due to the abrupt change in soil properties, which requires further modelling efforts to improve the smoothness of transition, reducing numerical issues and enhancing the realism of natural systems' representation. Further, the initial climate condition has a dominant role in the simulated soil temperature and liquid moisture content. In contrast, the initial water content (and its partitioning into liquid and frozen) had a stronger influence on the formed ice than the initial climate condition.

The assessment also incorporated different aspects that describe permafrost dynamics on annual basis, noting that previous studies on permafrost simulation in LSMs considered limited features of permafrost in their assessments. We selected two performance metrics, the bias in simulated active layer thickness (eALT) and the root mean square error (RMSE) of temperature envelopes, to examine the impact of different spinning conditions on the simulation quality. eALT showed high dependency on soil-texture, and landcover parameterizations, with systematic errors in the range of $\pm 1 \mathrm{~m}$ observed at the two sites. Also, RMSEs of maximum and minimum annual temperature envelopes (Tmax and Tmin) varied by $\sim 1.5{ }^{\circ} \mathrm{C}$ and $\sim 0.75^{\circ} \mathrm{C}$ at the two sites, noting that the two sites yielded poorer RMSE of Tmin compared to Tmax. The mean annual ground temperature at the permafrost table (MAGTp) showed a stronger response to the driving climate over initial soil storage components, ranging between $2-3{ }^{\circ} \mathrm{C}$ annually at the two sites. Examining the temporal evolution of freezing/thawing cycles highlighted the high variability of the date of maximum thaw (ALT-DOY), shifting by up to four weeks between August and October. The depth of the zero-annual temperature amplitude (DZAA) and the depth to the base of permafrost (BP) exhibited similar responses to the initialization's uncertainty, as the results indicate considerable variability to the initial soil moisture, with a minor impact of the initial climate condition, having a magnitude of variability of three- to four-fold among all the designed experiments.

Notably, modelers employ different initialization techniques to generate self-consistent model states, which are assumed sufficient for the subsequent simulation once it attains quasi-equilibrium. The main assumption at the start of model initialization is the presence of a quasi-equilibrium with the external forcing. However, the atmospheric climate has been transient over the last millennium (Mann et al. , 1999) and is in strong disequilibrium with the 'transient' ground thermal regime at decadal-to-millennial scales (Zhang et al. , 2008b). In the current study, we followed the same conventional approach of assuming an equilibrium state at the end of the successful spinning. However, the study showed that there are several self-consistent states, generated under different initial conditions, which would yield divergent simulations of permafrost. This outcome raises the fundamental issue of attempting to initialize models to a steady state while the real system is transient, which yet has no simple resolution. 
To conclude, our study accentuated the importance of LSM initialization for permafrost-related analysis, which could alter state-variable stabilization and, therefore, the simulation itself. The work assessed the propagation of initialization uncertainty on different aspects characterizing permafrost dynamics and underscored the huge variability in permafrost simulation. In terms of simulation quality, the two setups were able to produce Tmax envelopes and ALTs in reasonable agreement with observation, which is not the case for Tmin envelopes that were colder than observed. The relatively poor simulated cold soil envelope (Tmin) suggests inadequate surface insulation that could be attributed to the quality of snow simulation, which can be addressed through integrating a multi-layer snow scheme (e.g. JULES: Burke et al. , 2013), a complex canopies module (e.g. CLASS-CTEM: Melton et al. , 2019), and/or representing the lateral migration of heat/moisture fluxes (e.g.Noah-MP: Aas et al. , 2019). Therefore, further development is needed in MESH/CLASS to elevate the realism of permafrost simulations, and consequently, the hydrologic and climate simulations. Future work can be directed towards generalizing our analysis outcomes to other observational sites in other permafrost regions/classes, and extension to different regional and global models with varying complexity levels in large-scale applications. Lastly, assessing the influence of LSM parameters on simulated permafrost through a comprehensive sensitivity analysis is recommended in light of the large impact of initial conditions on LSM permafrost simulation.

\section{ACKNOWLEDGMENTS}

This research was supported financially by the Canada Excellence Research Chair (CERC) Programme in Water Security, and the Natural Sciences and Engineering Research Council of Canada (NSERC) federal funding. The authors would like to thank the Information \& Communications Technology (ICT) at the University of Saskatchewan, for providing continuous support in using the High-Performance Computing (HPC) research cluster, Plato.

\section{REFERENCES}

Aas KS, Martin L, Nitzbon J, Langer M, Boike J, Lee H, Berntsen TK, Westermann S. 2019. Thaw processes in ice-rich permafrost landscapes represented with laterally coupled tiles in a land surface model.Cryosphere 13 (2): 591-609 DOI: 10.5194/tc-13-591-2019

Alexeev VA, Nicolsky DJ, Romanovsky VE, Lawrence DM. 2007. An evaluation of deep soil configurations in the CLM3 for improved representation of permafrost. Geophysical Research Letters 34 (9) DOI: 10.1029/2007GL029536

Anisimov OA, Shiklomanov NI, Nelson FE. 2002. Variability of seasonal thaw depth in permafrost regions: A stochastic modeling approach.Ecological Modelling 153 (3): 217-227 DOI: 10.1016/S0304-3800(02)00016-9

Burke EJ, Dankers R, Jones CD, Wiltshire AJ. 2013. A retrospective analysis of pan Arctic permafrost using the JULES land surface model. Climate Dynamics 41 (3-4): 1025-1038 DOI: 10.1007/s00382-012-1648-x

Burke EJ, Zhang Y, Krinner G. 2020. Evaluating permafrost physics in the Coupled Model Intercomparison Project 6 (CMIP6) models and their sensitivity to climate change. The Cryosphere 14 (9): 3155-3174 DOI: $10.5194 /$ tc-14-3155-2020

Burn CR, Nelson FE. 2006. Comment on 'a projection of severe near-surface permafrost degradation during the 21st century' by David M. Lawrence and Andrew G. Slater. Geophysical Research Letters33 (21): L21503 DOI: $10.1029 / 2006 G L 027077$

Centre for Land and Biological Resources Research 1996. Soil Landscapes of Canada, v.2.2, Research Branch, Agriculture and Agri-Food Canada, Ottawa, Canada 
Chadburn SE, Burke EJ, Essery RLH, Boike J, Langer M, Heikenfeld M, Cox PM, Friedlingstein P. 2015. Impact of model developments on present and future simulations of permafrost in a global land-surface model.Cryosphere 9 (4): 1505-1521 DOI: 10.5194/tc-9-1505-2015

Chartrand J, Ednie M, Smith SL, Duchesne C, Riseborough DW. 2014. Report on 2013 field activities and collection of ground thermal and active layer data in the Mackenzie Corridor. Geological Survey of Canada, Open File 7659, Ottawa, Canada. DOI: 10.4095/295596

Chen F, Dudhia J. 2001. Coupling an Advanced Land Surface-Hydrology Model with the Penn StateNCAR MM5 Modeling System. Part I: Model Implementation and Sensitivity. MONTHLY WEATHER REVIEW 129 : 569-585

Connon R, Devoie É, Hayashi M, Veness T, Quinton W. 2018. The Influence of Shallow Taliks on Permafrost Thaw and Active Layer Dynamics in Subarctic Canada. Journal of Geophysical Research: Earth Surface $\mathbf{1 2 3}$ (2): 281-297 DOI: 10.1002/2017JF004469

Cosby BJ, Hornberger GM, Clapp RB, Ginn TR. 1984. A Statistical Exploration of the Relationships of Soil Moisture Characteristics to the Physical Properties of Soils. Water Resources Research 20 (6): 682-690

Cosgrove BA, Lohmann D, Mitchell KE, Houser PR, Wood EF, Schaake JC, Robock A, Sheffield J, Duan Q, Luo L, et al. 2003. Land surface model spin-up behavior in the North American Land Data Assimilation System (NLDAS). Journal of Geophysical Research D: Atmospheres108 (22) DOI: 10.1029/2002jd003316

Côté J, Desmarais JG, Gravel S, Méthot A, Patoine A, Roch M, Staniforth A. 1998. The operational CMCMRB global environmental multiscale (GEM) model. Part II: Results. Monthly Weather Review 126 (6): 1397-1418 DOI: 10.1175/1520-0493(1998)126<1397:TOCMGE > 2.0.CO;2

Dankers R, Burke EJ, Price J. 2011. Simulation of permafrost and seasonal thaw depth in the JULES land surface scheme. Cryosphere5 (3): 773-790 DOI: 10.5194/tc-5-773-2011

Davison B, Pietroniro A, Fortin V, Leconte R, Mamo M, Yau MK. 2016. What is Missing from the Prescription of Hydrology for Land Surface Schemes? Journal of Hydrometeorology 17 (7): 2013-2039 DOI: 10.1175/JHM-D-15-0172.1

DeBeer CM, Wheater HS, Carey SK, Chun KP. 2016. Recent climatic, cryospheric, and hydrological changes over the interior of western Canada: A review and synthesis. Hydrology and Earth System Sciences 20 (4): 1573-1598 DOI: 10.5194/hess-20-1573-2016

Devoie ÉG, Craig JR, Connon RF, Quinton WL. 2019. Taliks: A Tipping Point in Discontinuous Permafrost Degradation in Peatlands. Water Resources Research 55 (11): 9838-9857 DOI: 10.1029/2018WR024488

Dobinski W. 2011. Permafrost. Earth-Science Reviews 108 : 158-169 DOI: 10.1016/j.earscirev.2011.06.007

Ednie M, Chartrand J, Smith SL, Duchesne C, Riseborough DW. 2012. Report on 2011 Field Activities and Collection of Ground Thermal and Active Layer Data in the Mackenzie Corridor Completed Under Northwest Territories Science Licence \#14918. Geological Survey of Canada, Open File 7231, Ottawa, Canada. DOI: $10.4095 / 291982$

Elshamy ME, Princz D, Sapriza-Azuri G, Abdelhamed MS, Pietroniro A, Wheater HS, Razavi S. 2020. On the configuration and initialization of a large-scale hydrological land surface model to represent permafrost.Hydrology and Earth System Sciences 24 (1): 349-379 DOI: 10.5194/hess-24-349-2020

Everdingen RO. 1998. MULTI-LANGUAGE GLOSSARY of PERMAFROST and RELATED GROUNDICE TERMS. Calgary, Alberta, CANADA T2N 1N4. DOI: 10.2307/1551636

de Goncalves LGG, Shuttleworth WJ, Burke EJ, Houser P, Toll DL, Rodell M, Arsenault K. 2006. Toward a South America Land Data Assimilation System: Aspects of land surface model spin-up using the Simplified Simple Biosphere. Journal of Geophysical Research Atmospheres111 (17): 1-13 DOI: 10.1029/2005JD006297 
Haghnegahdar A, Tolson BA, Davison B, Seglenieks FR, Klyszejko E, Soulis ED, Fortin V, Matott LS. 2014. Calibrating environment Canada's MESH modelling system over the Great Lakes Basin. Atmosphere - Ocean52 (4): 281-293 DOI: 10.1080/07055900.2014.939131

Hermoso de Mendoza I, Beltrami H, MacDougall AH, Mareschal J-C. 2020. Lower boundary conditions in land surface models - effects on the permafrost and the carbon pools: a case study with CLM4.5.Geoscientific Model Development 13 (3): 1663-1683 DOI: 10.5194/gmd-13-1663-2020

Hjort J, Karjalainen O, Aalto J, Westermann S, Romanovsky VE, Nelson FE, Etzelmüller B, Luoto M. 2018. Degrading permafrost puts Arctic infrastructure at risk by mid-century. Nature Communications 9 (1) DOI: 10.1038/s41467-018-07557-4

Husain SZ, Alavi N, Bélair S, Carrera M, Zhang S, Fortin V, Abrahamowicz M, Gauthier N. 2016. The Multibudget Soil, Vegetation, and Snow (SVS) Scheme for Land Surface Parameterization: Offline Warm Season Evaluation. Journal of Hydrometeorology 17 (8): 2293-2313 DOI: 10.1175/JHM-D-15-0228.1

Jafarov EE, Marchenko SS, Romanovsky VE. 2012. Numerical modeling of permafrost dynamics in Alaska using a high spatial resolution dataset.Cryosphere 6 (3): 613-624 DOI: 10.5194/tc-6-613-2012

Keshav K, Haghnegahdar A, Elshamy M, Gharari S, Razavi S. 2019a. Aggregated gridded soil texture dataset for Mackenzie and Nelson-Churchill River Basins, Federated Research Data Repository (FRDR), Canada, https://doi.org/10.20383/101.0154

Keshav K, Haghnegahdar A, Elshamy M, Gharari S, Razavi S. 2019b. Bedrock depth dataset for NelsonChurchill and Mackenzie River Basin based on bedrock data by Shangguan et al. (2016), Federated Research Data Repository (FRDR), Canada, https://doi.org/10.20383/101.0152

Kouwen N, Soulis ED, Pietroniro A, Donald J, Harrington RA. 1993a. Grouped response units for distributed hydrologic modelling. Journal of Water Resources Planning and Management 119(3): 289-305

Kouwen N, Soulis R, Seglenieks F, Bingeman A, Davison B. 1993b. An Introduction to WATFLOOD and WATCLASS: $1-13$

Lamontagne-Hallé P, McKenzie JM, Kurylyk BL, Molson J, Lyon LN. 2020. Guidelines for coldregions groundwater numerical modeling. Wiley Interdisciplinary Reviews: Water (June): 1-26 DOI: $10.1002 /$ wat 2.1467

Langer M, Westermann S, Heikenfeld M, Dorn W, Boike J. 2013. Satellite-based modeling of permafrost temperatures in a tundra lowland landscape. Remote Sensing of Environment 135 : 12-24 DOI: $10.1016 /$ j.rse.2013.03.011

Lawrence DM, Slater AG. 2005. A projection of severe near-surface permafrost degradation during the 21st century. Geophysical Research Letters 32 (24): 1-5 DOI: 10.1029/2005GL025080

Lawrence DM, Oleson KW, Flanner MG, Thornton PE, Swenson SC, Peter J, Zeng X, Yang Z, Levis S, Sakaguchi K, et al. 2011. Parameterization Improvements and Functional and Struc- tural Advances in Version 4 of the Community Land Model. Journal of Advances in Modeling Earth Systems 3 (1): 1-27 DOI: 10.1029/2011MS000045

Lawrence DM, Slater AG, Romanovsky VE, Nicolsky DJ. 2008. Sensitivity of a model projection of nearsurface permafrost degradation to soil column depth and representation of soil organic matter. Journal of Geophysical Research: Earth Surface 113 (2): 1-14 DOI: 10.1029/2007JF000883

Lawrence DM, Slater AG, Swenson SC. 2012. Simulation of present-day and future permafrost and seasonally frozen ground conditions in CCSM4.Journal of Climate 25 (7): 2207-2225 DOI: 10.1175/JCLI-D-11-00334.1

Letts MG, Comer NT, Roulet NT, Skarupa MR, Verseghy DL. 2000. Parametrization of peatland hydraulic properties for the Canadian land surface scheme. Atmosphere - Ocean 38 (1): 141-160 DOI: $10.1080 / 07055900.2000 .9649643$ 
Mahfouf JF, Brasnett B, Gagnon S. 2007. A Canadian precipitation analysis (CaPA) project: Description and preliminary results.Atmosphere - Ocean 45 (1): 1-17 DOI: 10.3137/ao.v450101

Mann ME, Bradley RS, Hughes MK. 1999. Northern hemisphere temperatures during the past millennium: Inferences, uncertainties, and limitations. Geophysical Research Letters 26 (6): 759-762

McGuire AD, Lawrence DM, Koven C, Clein JS, Burke E, Chen G, Jafarov E, MacDougall AH, Marchenko S, Nicolsky D, et al. 2018. Dependence of the evolution of carbon dynamics in the northern permafrost region on the trajectory of climate change. Proceedings of the National Academy of Sciences of the United States of America 115 (15): 3882-3887 DOI: 10.1073/pnas.1719903115

Mekonnen MA, Wheater HS, Ireson AM, Spence C, Davison B, Pietroniro A. 2014. Towards an improved land surface scheme for prairie landscapes. Journal of Hydrology 511 : 105-116 DOI: 10.1016/j.jhydrol.2014.01.020

Melton JR, Verseghy DL, Sospedra-Alfonso R, Gruber S. 2019. Improving permafrost physics in the coupled Canadian Land Surface Scheme (v.3.6.2) and Canadian Terrestrial Ecosystem Model (v.2.1) (CLASSCTEM).Geoscientific Model Development 12 (10): 4443-4467 DOI: 10.5194/gmd-12-4443-2019

Meredith M, Sommerkorn M, Cassotta S, Derksen C, Ekaykin A, Hollowed A, Kofinas G, Mackintosh A, Melbourne-Thomas J, Muelbert MMC, et al. 2020. Polar regions. In IPCC Special Report on the Ocean and Cryosphere in a Changing Climate, , Pörtner H-O, , Roberts DC, , Masson-Delmotte V, , Zhai P, , Tignor M, , Poloczanska E, , Mintenbeck K, , Alegría A, , Nicolai M, , Okem A, et al. (eds).203-320. DOI: 10.1016/S1366-7017(01)00066-6

Nelson FE, Anisimov OA, Shiklomanov NI. 2002. Climate change and hazard zonation in the circum-arctic permafrost regions. Natural Hazards26 (3): 203-225 DOI: 10.1023/A:1015612918401

Nicolsky DJ, Romanovsky VE, Alexeev VA, Lawrence DM. 2007. Improved modeling of permafrost dynamics in a GCM land-surface scheme. Geophysical Research Letters 34 (8): 2-6 DOI: 10.1029/2007GL029525

Nishimura S, Martin CJ, Jardine RJ, Fenton CH. 2009. A new approach for assessing geothermal response to climate change in permafrost regions. Geotechnique 59 (3): 213-227 DOI: 10.1680/geot.2009.59.3.213

Niu G-Y, Yang Z-L. 2006. Effects of Frozen Soil on Snowmelt Runoff and Soil Water Storage at a Continental Scale. Journal of Hydrometeorology 7 (5): 937-952 DOI: 10.1175/JHM538.1

Obu J, Westermann S, Bartsch A, Berdnikov N, Christiansen HH, Dashtseren A, Delaloye R, Elberling B, Etzelmüller B, Kholodov A, et al. 2019. Northern Hemisphere permafrost map based on TTOP modelling for 2000-2016 at $1 \mathrm{~km} 2$ scale. Earth-Science Reviews 193 : 299-316 DOI: 10.1016/j.earscirev.2019.04.023

Oldenborger GA, LeBlanc A-M, Stevens CW, Chartrand J, Loranger B. 2015. Geophysical surveys, permafrost conditions and infrastructure damage along the northern Yukon Alaska Highway, Open File 7875 DOI: $10.4095 / 296704$

Oleson KW, Lawrence DM, Bonan GB, Drewniak B, Huang M, Charles D, Levis S, Li F, Riley WJ, Zachary M, et al. 2013. Technical Description of version 4.5 of the Community Land Model (CLM) DOI: 10.5065/D6RR1W7M

Pan X, Li Y, Yu Q, Shi X, Yang D, Roth K. 2016. Effects of stratified active layers on high-altitude permafrost warming: A case study on the Qinghai-Tibet Plateau. Cryosphere 10 (4): 1591-1603 DOI: 10.5194/tc-101591-2016

Park H, Walsh J, Fedorov AN, Sherstiukov AB, Iijima Y, Ohata T. 2013. The influence of climate and hydrological variables on opposite anomaly in active-layer thickness between Eurasian and North American watersheds. The Cryosphere 7 (2): 631-645 DOI: 10.5194/tc-7-631-2013

Peel MC, Finlayson BL, McMahon TA. 2007. Updated world map of the Köppen-Geiger climate classification. Hydrology and Earth System Sciences 11 : 1633-1644 DOI: https://doi.org/10.5194/hess-11-1633-2007 
Pietroniro A, Fortin V, Kouwen N, Neal C, Turcotte R, Davison B, Verseghy DL, Soulis ED, Caldwell R, Evora N, et al. 2007. Development of the MESH modelling system for hydrological ensemble forecasting of the Laurentian Great Lakes at the regional scale. Hydrology and Earth System Sciences 11 (4): 1279-1294 DOI: 10.5194/hess-11-1279-2007

Quinton WL, Marsh P. 1999. A conceptual framework for runoff generation in a permafrost environment. Hydrological Processes 13(16 SPEC. ISS.): 2563-2581 DOI: 10.1002/(SICI)1099-1085(199911)13:16<2563::AIDHYP942>3.0.CO;2-D

Razavi S, Tolson BA, Matott LS, Thomson NR, MacLean A, Seglenieks FR. 2010. Reducing the computational cost of automatic calibration through model preemption. Water Resources Research 46 (11): 1-17 DOI: $10.1029 / 2009 W R 008957$

Riseborough D, Shiklomanov N, Etzelmuller B, Gruber S, Marchenko S. 2008. Recent Advances in Permafrost Modelling. Permafrost and periglacial processes 19 : 137-156 DOI: 10.1002/ppp.615

Rodell M, Houser PR, Berg AA, Famiglietti JS. 2005. Evaluation of 10 methods for initializing a land surface model. Journal of Hydrometeorology 6 (2): 146-155 DOI: 10.1175/JHM414.1

Sapriza-Azuri G, Gamazo P, Razavi S, Wheater HS. 2018. On the appropriate definition of soil profile configuration and initial conditions for land surface-hydrology models in cold regions.Hydrology and Earth System Sciences 22 (6): 3295-3309 DOI: 10.5194/hess-22-3295-2018

Schuur EAG, Bockheim J, Canadell JG, Euskirchen E, Field CB, Goryachkin S V., Hagemann S, Kuhry P, Lafleur PM, Lee H, et al. 2008. Vulnerability of Permafrost Carbon to Climate Change: Implications for the Global Carbon Cycle. BioScience 58 (8): 701-714 DOI: 10.1641/b580807

Schuur EAG, McGuire AD, Schädel C, Grosse G, Harden JW, Hayes DJ, Hugelius G, Koven CD, Kuhry P, Lawrence DM, et al. 2015. Climate change and the permafrost carbon feedback. Nature $\mathbf{5 2 0}$ (7546): 171-179 DOI: $10.1038 /$ nature14338

Sheffield J, Goteti G, Wood EF. 2006. Development of a 50-year high-resolution global dataset of meteorological forcings for land surface modeling. Journal of Climate 19 (13): 3088-3111 DOI: 10.1175/JCLI3790.1

Shrestha R, Houser P. 2010. A heterogeneous land surface model initialization study. Journal of Geophysical Research Atmospheres115 (19): 1-10 DOI: 10.1029/2009JD013252

Smith SL, Burgess MM, Riseborough D, Coultish T, Chartrand J. 2004. Digital Summary Database of Permafrost and Thermal Conditions - Norman Wells Pipeline Study Sites. Geological Survey of Canada, Open File 4635, Ottawa, Canada.

Smith SL, Chartrand J, Duchesne C, Ednie M. 2016. Report on 2015 field activities and collection of ground thermal and active layer data in the Mackenzie Corridor, Northwest Territories. Geological Survey of Canada, Open File 8125, Ottawa, Canada. DOI: 10.4095/299296

Smith SL, Chartrand J, Nguyen T-N, Riseborough DW, Ednie M, Ye S. 2009. Geotechnical database and descriptions of permafrost monitoring sites established 2006-07 in the central and southern Mackenzie Corridor. Geological Survey of Canada, Open File 6041, Ottawa, Canada.

Smith SL, Throop J, Ednie M, Chartrand J, Riseborough DW, Nixon FM. 2010. Report on 2009 Field Activities and Ground Thermal Data Collection in the Mackenzie Corridor Completed Under N.W.T. Science Licence \# 14582. Geological Survey of Canada, Open File 6695, Ottawa, Canada.

Soulis ED, Snelgrove KR, Kouwen N, Seglenieks F, Verseghy DL. 2000. Towards closing the vertical water balance in Canadian atmospheric models: Coupling of the land surface scheme class with the distributed hydrological model watflood. Atmosphere - Ocean 38 (1): 251-269 DOI: 10.1080/07055900.2000.9649648

Takata K. 2002. Sensitivity of land surface processes to frozen soil permeability and surface water storage. Hydrological Processes 16 (11): 2155-2172 DOI: 10.1002/hyp.1148 
Taylor AE, Wang K, Smith SL, Burgess MM, Judge AS. 2006. Canadian Arctic Permafrost Observatories: Detecting contemporary climate change through inversion of subsurface temperature time series. Journal of Geophysical Research: Solid Earth 111 (2) DOI: 10.1029/2004JB003208

U.S. Department of Agriculture 1951. Soil survey manual, USDA Handbook 18. Washington, D.C.: Government Printing Office

Verseghy D. 2012. CLASS - The Canadian land surface scheme (version 3.6) - technical documentation

Verseghy DL. 1991. Canadian Land Surface Scheme for GCMS I. Soil model.International Journal of Climatology 11 : 111-133 DOI: 10.1002/joc.3370110202

Verseghy DL. 2000. The Canadian land surface scheme (CLASS): Its history and future. Atmosphere-Ocean 38 (1): 1-13 DOI: 10.1080/07055900.2000.9649637

Walker JP, Houser PR. 2001. A methodology for initializing soil moisture in a global climate model: Assimilation of near-surface soil moisture observations. Journal of Geophysical Research Atmospheres106 (D11): 11761-11774 DOI: 10.1029/2001JD900149

Walvoord MA, Kurylyk BL. 2016. Hydrologic Impacts of Thawing Permafrost-A Review. Vadose Zone Journal 15 (6): 0 DOI: 10.2136/vzj2016.01.0010

Walvoord MA, Striegl RG. 2007. Increased groundwater to stream discharge from permafrost thawing in the Yukon River basin: Potential impacts on lateral export of carbon and nitrogen. Geophysical Research Letters 34 (12) DOI: 10.1029/2007GL030216

Weedon GP, Balsamo G, Bellouin N, Gomes S, Best MJ, Viterbo P. 2014. The WFDEI meteorological forcing data set: WATCH Forcing Data methodology applied to ERA-Interim reanalysis data. Water Resources Research50 : 7505-7514 DOI: 10.1002/2014WR015638

Weedon GP, Gomes S, Viterbo P, Shuttleworth WJ, Blyth E, ÖSterle H, Adam JC, Bellouin N, Boucher O, Best M. 2011. Creation of the WATCH forcing data and its use to assess global and regional reference crop evaporation over land during the twentieth century. Journal of Hydrometeorology 12 (5): 823-848 DOI: 10.1175/2011JHM1369.1

Wei S, Yongjiu D, Qingyun D, Baoyuan L, Hua Y. 2014. A global soil data set for earth system modeling. Journal of Advances in Modeling Earth Systems 6 : 249-263 DOI: 10.1002/2013MS000293

Wong JS, Razavi S, Bonsal BR, Wheater HS, Asong ZE. 2017. Inter-comparison of daily precipitation products for large-scale hydro-climatic applications over Canada. Hydrology and Earth System Sciences 21 (4): 2163-2185 DOI: 10.5194/hess-21-2163-2017

Woo MK. 2012. Permafrost hydrology . Springer Science \& Business Media. DOI: 10.1007/978-3-642-23462-0

Wright JF, Duchesne C, Côté MM. 2003. Regional-scale permafrost mapping using the TTOP ground temperature model. In Proceedings 8th International Conference on Permafrost 1241-1246. Available at: http://research.iarc.uaf.edu/NICOP/DVD/ICOP 2003 Permafrost/Pdf/Chapter_218.pdf

Wu Q, Zhang T, Liu Y. 2010. Permafrost temperatures and thickness on the Qinghai-Tibet Plateau. Global and Planetary Change 72(1-2): 32-38 DOI: 10.1016/j.gloplacha.2010.03.001

Wu X, Nan Z, Zhao S, Zhao L, Cheng G. 2018. Spatial modeling of permafrost distribution and properties on the Qinghai-Tibet Plateau.Permafrost and Periglacial Processes 29 (2): 86-99 DOI: 10.1002/ppp.1971

Wu Y, Verseghy DL, Melton JR. 2016. Integrating peatlands into the coupled Canadian Land Surface Scheme (CLASS) v3.6 and the Canadian Terrestrial Ecosystem Model (CTEM) v2.0. Geoscientific Model Development 9 (8): 2639-2663 DOI: 10.5194/gmd-9-2639-2016

Yang Z-LL, Dickinson RE, Henderson-Selles A, Pitman AJ, Henderson-Sellers a., Pitman AJ. 1995. Preliminary study of spin-up processes in land surface models with the first stage data of project for intercomparison 
of land surface parameterization schemes phase 1(a). Journal of Geophysical Research 100 (D8): 16553 DOI: 10.1029/95jd01076

Yassin F, Razavi S, Wheater H, Sapriza-Azuri G, Davison B, Pietroniro A. 2017. Enhanced identification of a hydrologic model using streamflow and satellite water storage data: A multicriteria sensitivity analysis and optimization approach. Hydrological Processes 31 (19): 3320-3333 DOI: 10.1002/hyp.11267

Zhang T, Barry RG, Knowles K, Heginbottom JA, Brown J. 1999. Statistics and characteristics of permafrost and ground-ice distribution in the Northern Hemisphere. Polar Geography 23 (2): 132-154 DOI: $10.1080 / 10889370802175895$

Zhang T, Frauenfeld OW, Serreze MC, Etringer A, Oelke C, McCreight J, Barry RG, Gilichinsky D, Yang D, Ye H, et al. 2005. Spatial and temporal variability in active layer thickness over the Russian Arctic drainage basin. Journal of Geophysical Research D: Atmospheres110 (16): 1-14 DOI: 10.1029/2004JD005642

Zhang Y, Carey SK, Quinton WL. 2008a. Evaluation of the algorithms and parameterizations for ground thawing and freezing simulation in permafrost regions. Journal of Geophysical Research Atmospheres113 (17): 1-17 DOI: 10.1029/2007JD009343

Zhang Y, Chen W, Riseborough DW. 2008b. Disequilibrium response of permafrost thaw to climate warming in Canada over 1850-2100. Geophysical Research Letters 35 (2): 2-5 DOI: 10.1029/2007GL032117

Zhang Y, Wang X, Fraser R, Olthof I, Chen W, McLennan D, Ponomarenko S, Wu W. 2013. Modelling and mapping climate change impacts on permafrost at high spatial resolution for an Arctic region with complex terrain. Cryosphere 7 (4): 1121-1137 DOI: 10.5194/tc-7-1121-2013

\section{TABLES}

Table 1. List of variables used to represent permafrost dynamics, visualized in

Fig. 1.

\begin{tabular}{lll}
\hline Symbol & Full name & Description \\
\hline Tmax/Tmin & Soil temperature envelopes & maximum and minimum soil temperature prc \\
MAGTp & Mean Annual Ground Temperature at the top of permafrost & mean annual ground temperature, taken at t \\
ALT & Active layer thickness & maximum depth of the 0 $0^{\circ}$ isotherm over the \\
DZAA & Depth of the Zero-Annual Amplitude & where the two envelopes (Tmax and Tmin) \\
BP & depth to the Base of Permafrost & where the temperature profiles intersect with \\
- & Thermal offset & the difference between the mean annual temp \\
- & Surface offset & the difference between the mean annual temp \\
ALT-DOY & Date of the maximum thaw & calculated from the evolution of daily temper \\
\hline
\end{tabular}

Table 2 . Summary of permafrost monitoring sites used in the study.

\begin{tabular}{lllllll}
\hline Site name & Borehole & Coordinates & Coordinates & Vegetation cover & Permafrost zone \\
\hline & & Lat. & Lon. & & & \\
Wrigley Highway & $99 \mathrm{TC} 03$ & 61.65 & -121.34 & Shrubs/ Moss/ Needleleaf forest & Discontinuous & \\
Jean Marie Creek & $85-12 \mathrm{~B}$ & 61.19 & -120.70 & Needleleaf forest/ Shrubs/ Moss & Sporadic & 1 \\
\hline
\end{tabular}

Table 3. Soil profile layering scheme for the two sites (adopted from (Elshamy et al. , 2020)). 


\begin{tabular}{llll}
\hline Layer & Thickness & Layer & Thickness \\
\hline 1 & 0.1 & 14 & 1.48 \\
2 & 0.1 & 15 & 1.78 \\
3 & 0.11 & 16 & 2.11 \\
4 & 0.13 & 17 & 2.48 \\
5 & 0.16 & 18 & 2.88 \\
6 & 0.21 & 19 & 3.33 \\
7 & 0.28 & 20 & 3.81 \\
8 & 0.37 & 21 & 4.34 \\
9 & 0.48 & 22 & 4.9 \\
10 & 0.63 & 23 & 5.51 \\
11 & 0.8 & 24 & 6.17 \\
12 & 0.99 & 25 & 6.87 \\
13 & 1.22 & & \\
\hline
\end{tabular}

Table 4. Climate conditions of the five representative hydrologic years used in the study for the two sites.

\begin{tabular}{llll}
\hline Climate condition & Jean Marie Creek (85-12-B) & Jean Marie Creek (85-12-B) & Jean Marie Creek (85-12- \\
\hline & Precipitation $\left(\mathbf{m m ~ y r}^{-\mathbf{1}}\right)$ & Temperature $\left({ }^{\circ} \mathbf{C}\right)$ & Year \\
Wet & 538.800 & -2.002 & $1987-1988$ \\
Dry & 260.935 & -1.994 & $1994-1995$ \\
Cold & 500.875 & -4.620 & $1981-1982$ \\
Warm & 441.456 & -0.754 & $1997-1998$ \\
Average & 410.161 & -2.799 & $1988-1989$ \\
\hline
\end{tabular}

\section{FIGURE LEGENDS}

Fig. 1. Schematic of the soil column showing variables used to represent permafrost dynamics, modified after (Dobinski, 2011; Burke et al. , 2020; Elshamyet al. , 2020).

Fig. 2. Location of the study area, temperature boreholes, and permafrost classification - the two selected sites are highlighted in the focused view.

Fig. 3. Permafrost's annual maximum and minimum temperature profiles for A) 85-12-B borehole, B) 99TC03 borehole.

Fig. 4. Detailed illustration of the model configuration in terms of antecedent water condition. Numbers between brackets above each bar correspond to the portions of liquid and frozen water content for each experiment, respectively.

Fig. 5 . Summary of the required number of spin-up cycles needed for model state variables to reach equilibrium for A) JMC, and B) WH. For each climate condition, the number of spin-up cycles is sorted in ascending order for all the 21 initial moisture scenarios in Fig. 4. Dashed lines separate the groups of climate experiments. Convergence criteria are $0.1^{\circ} \mathrm{C}$ for temperature and $0.01 \mathrm{~m}^{3} \mathrm{~m}^{-3}$ for liquid and frozen water.

Fig. 6. Temporal progression of spin-up convergence of soil temperature, soil liquid content, and soil frozen content at A) JMC site - Exp. Dry 7 (upper row), B) WH site - Exp. Wet 17 (middle row), and C) WH site - Exp. Avg 10 (lower row). Layers below SDEP have no moisture; only heat can transfer vertically between soil layers. 
Fig. 7. Summary of the required numbers of spin-up cycles needed by all state variables to reach equilibrium under different A) climate conditions, and B) initial soil moisture; only experiments that formed permafrost are included; black boxes correspond to the median of each group of experiments in subplot B. The configuration Id label is as inFig. 4 .

Fig. 8 . Comparison of A) cumulative daily precipitation, B) daily air temperature, C) histogram of daily air temperature based on the selected five climate conditions at WH site.

Fig. 9. Temporal variation in A) external forcing, B) soil temperature, C) soil liquid moisture content, and D) soil frozen moisture content for the first spin-up cycle under Average climate (right panel) and cold climate (left panel) for WH site.

Fig. 10. Soil temperature (column A and B), soil liquid content (column C), and soil frozen content (column D) at the end of the 2000 spin-up cycles at JMC site (upper panel) and WH site (lower panel); shading indicates the range of variability; each line represents an individual experiment; SDEP and ODEP indicate depth to the bedrock and depth to the organic matter, respectively. The presented state-variables are plotted at the middle of each soil layer. *: B is zooming into A to the depth shown for C \& D.

Fig. 11. Time series of the error in the simulated ALT, and the mean RMSE of the simulated annual temperature envelope (mean RMSE for Tmax and Tmin) among all the configurations at JMC site (column A), WH site (column B). Dashed lines separate the groups of climate experiments presented with the same numeric order as in Fig. 4 ; A: Average, C: Cold, D: Dry, Wr: Warm, and W: Wet. Gaps correspond to unavailable records.

Fig. 12. Time series of the RMSE of the simulated annual temperature envelopes. The lines represent the envelope mean, and the shadings represent the range of total variability because of the initial moisture's and climate conditions' uncertainties.

Fig. 13. Time series of the simulated A) MAGTp, B) ALT-DOY, C) DZAA, and D) PB at JMC site (upper panel), and WH site (lower panel), after the spin-up for 2000 cycles. The simulation label is as in Fig. 11 . 


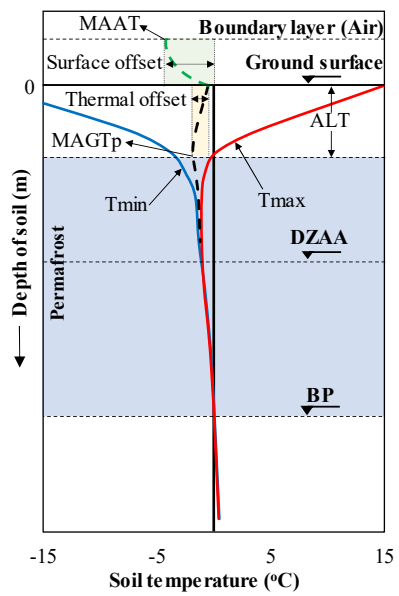




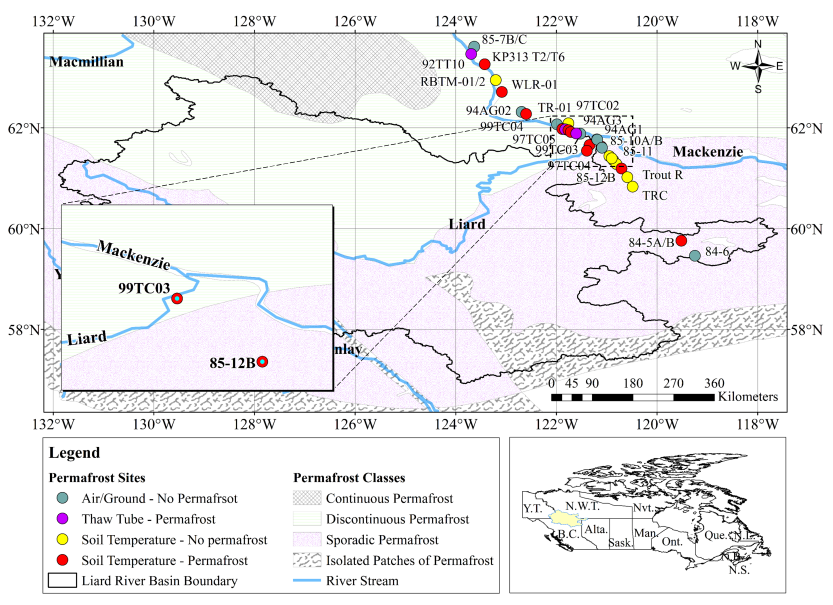



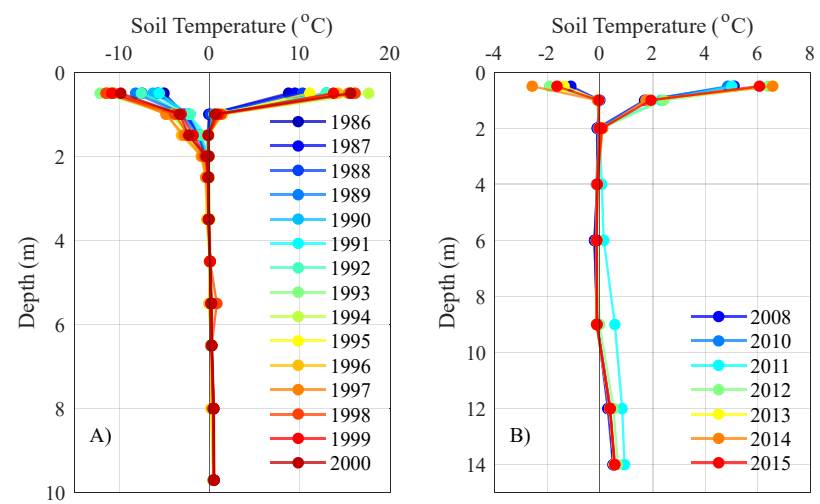


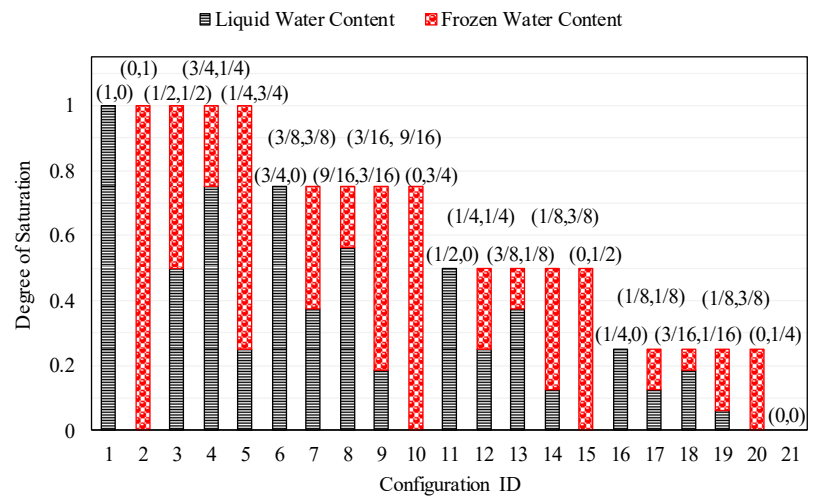




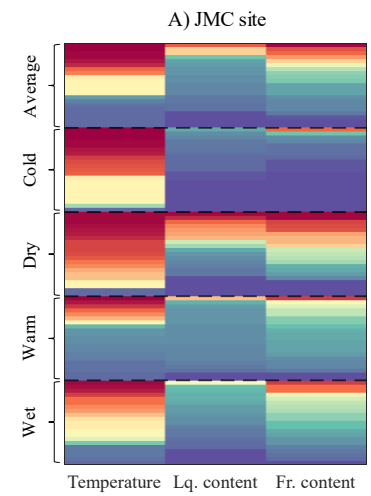

State variable
B) WH site

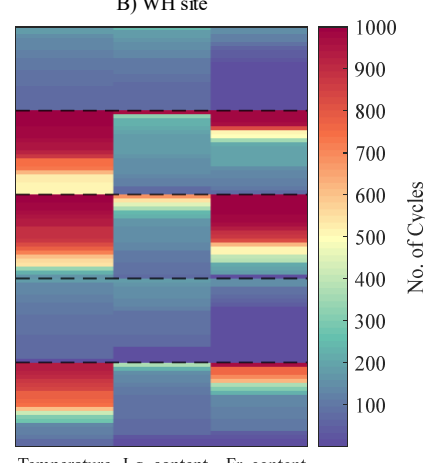

Temperature Lq. content Fr. content State variable 


\begin{tabular}{|c|c|c|c|c|c|c|}
\hline$-\mathrm{L} 1$ & $-\mathrm{L} 2$ & $-\mathrm{L} 3$ & L4 & - L5 & L6 & $-\mathrm{L} 7$ \\
\hline -L8 & $-\mathrm{L} 9$ & $-\mathrm{L} 10$ & L11 & L12 & L13 & -L14 \\
\hline $\begin{array}{r}\mathrm{L} 15 \\
-\mathrm{L} 22\end{array}$ & $\begin{array}{r}\text { L16 } \\
\end{array}$ & $\begin{array}{r}\text { L17 } \\
\end{array}$ & $\begin{array}{r}\mathrm{L} 18 \\
\mathrm{~L} 25\end{array}$ & L19 & $-\mathrm{L} 20$ & $\mathrm{~L} 21$ \\
\hline
\end{tabular}
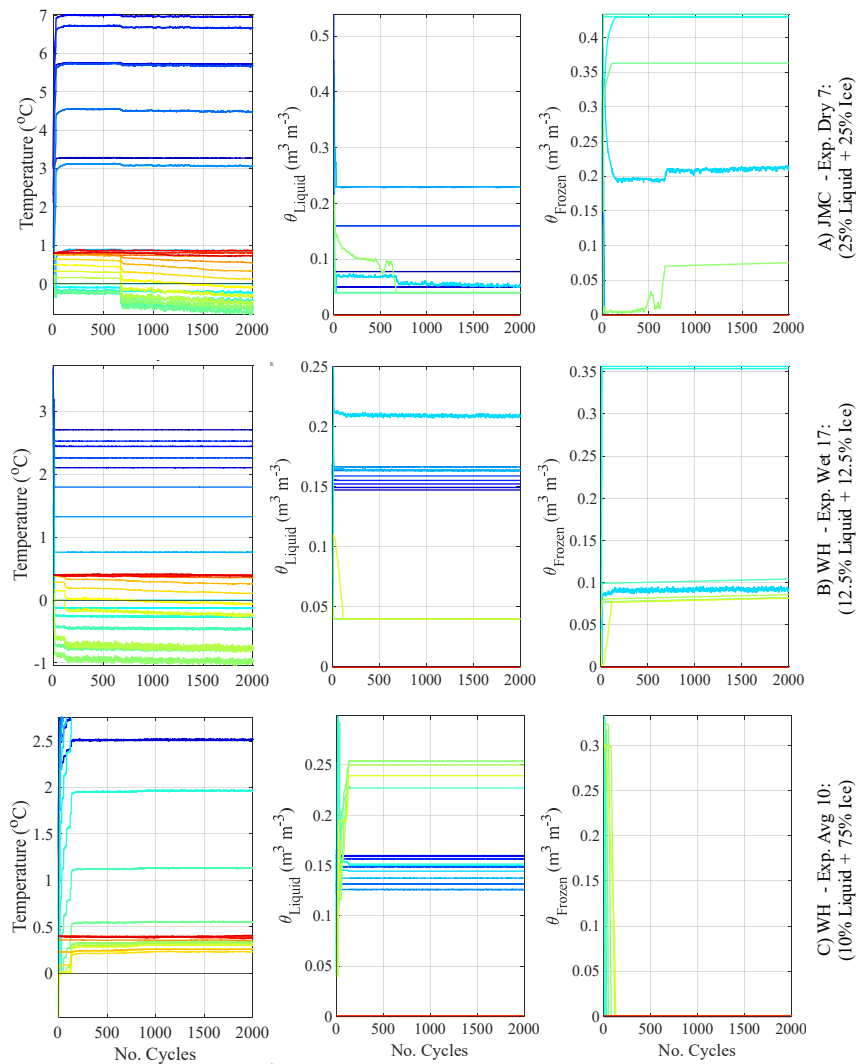

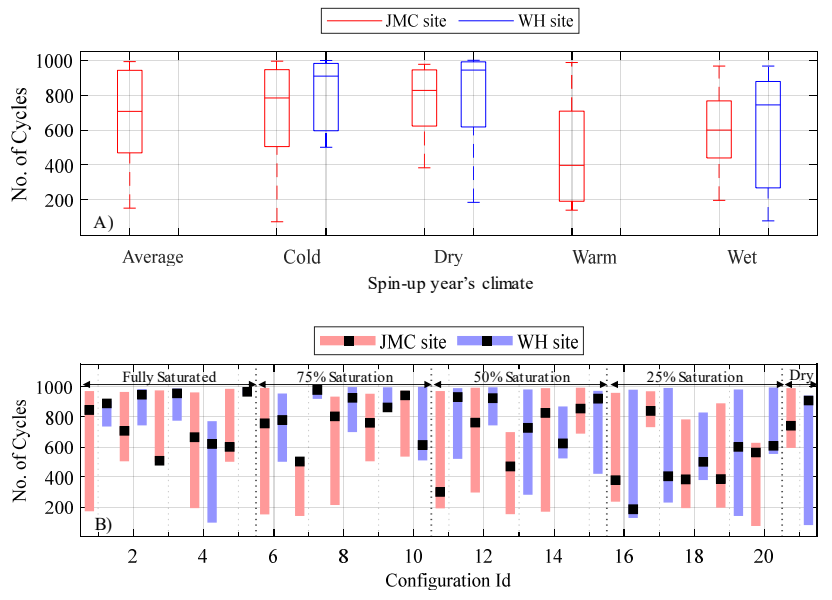

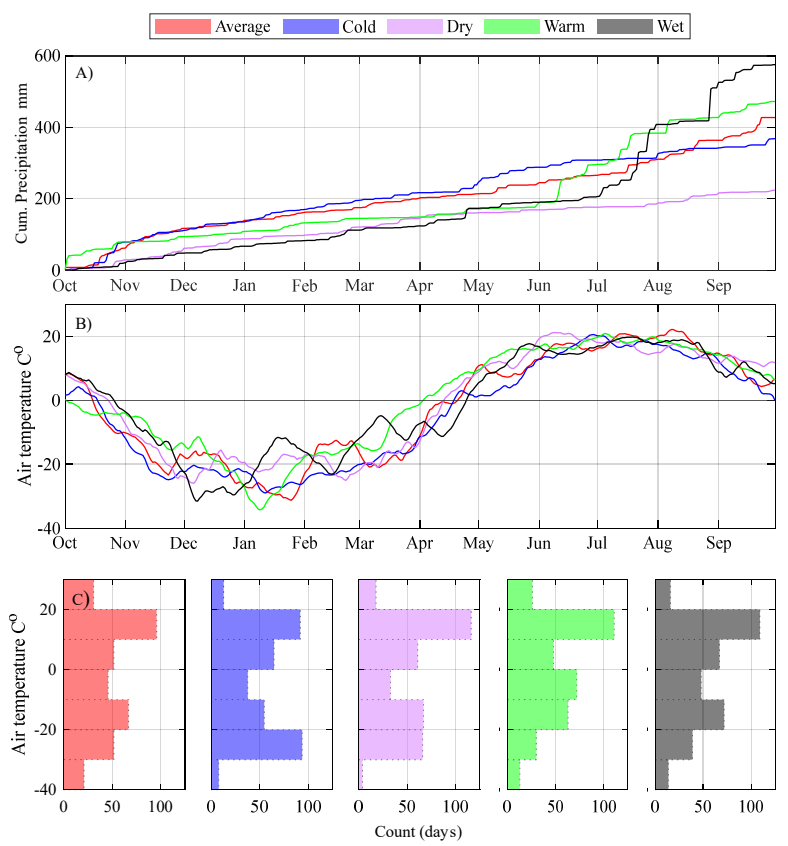


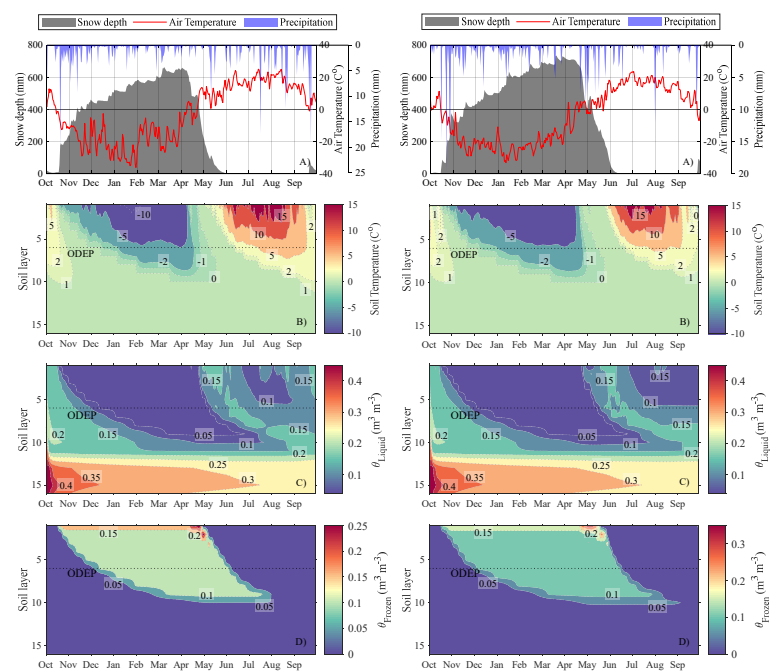




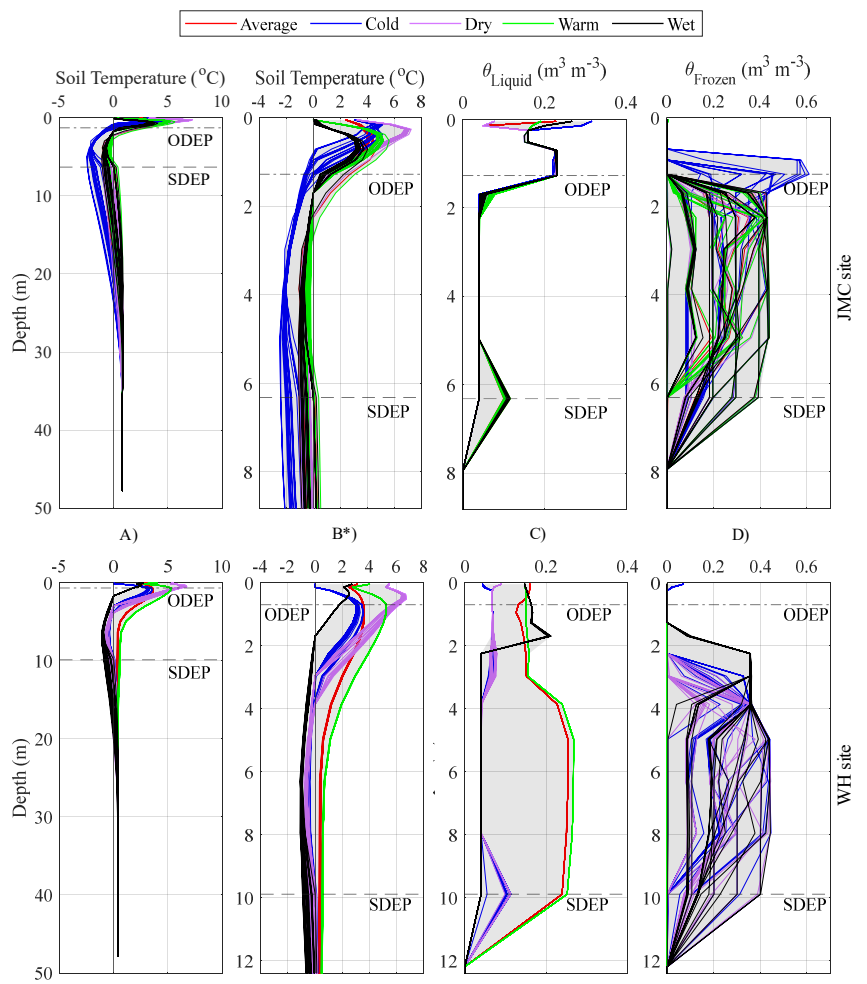



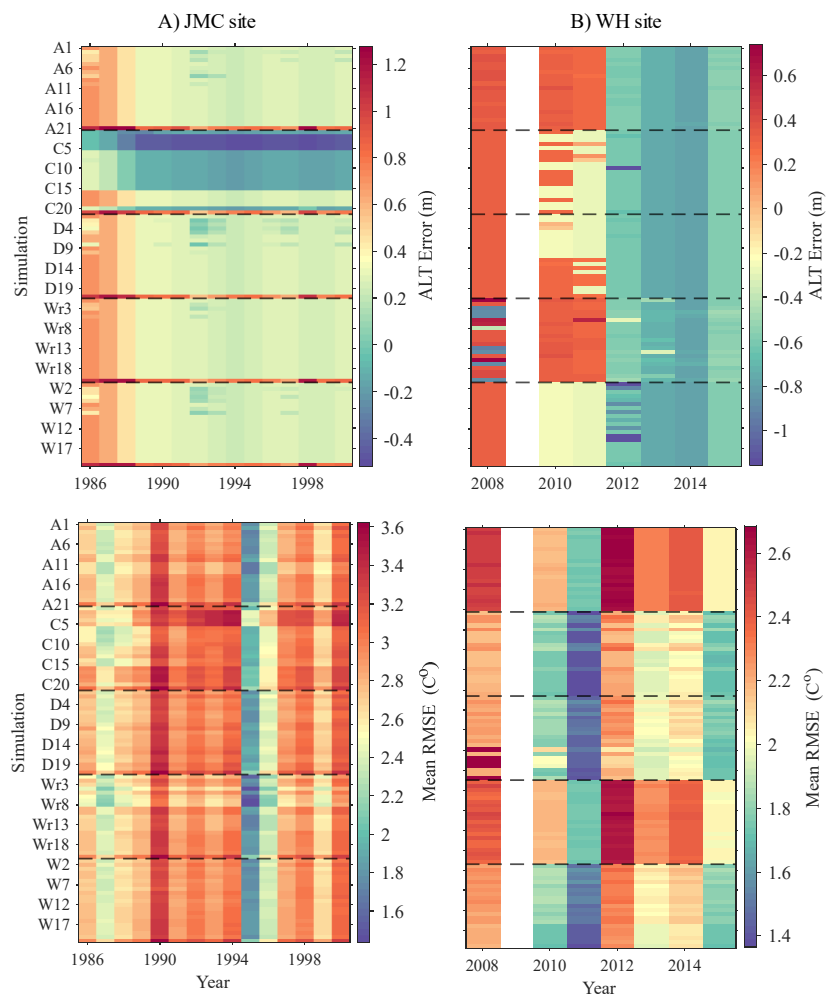


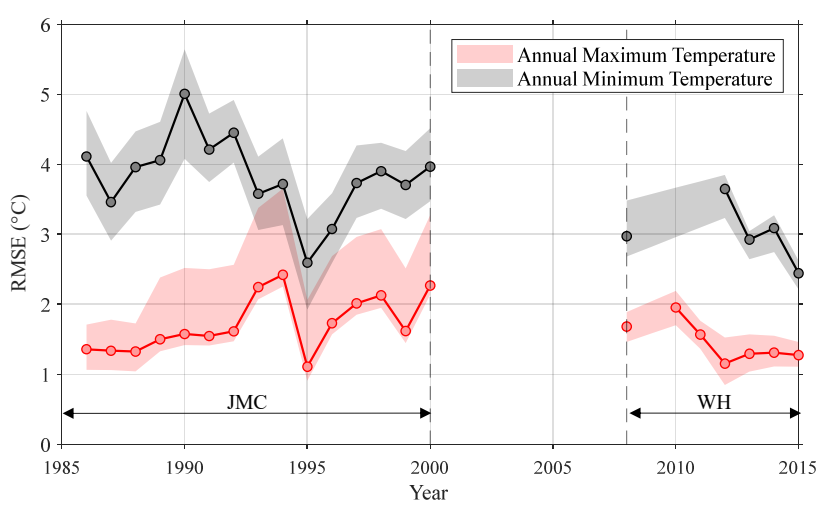



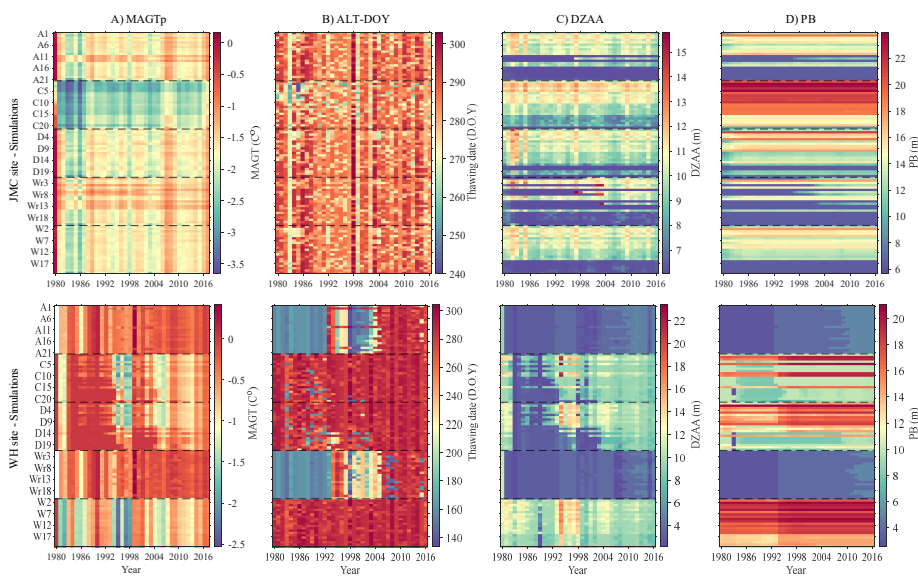